\title{
Elucidating the Stability and Reactivity of Surface Intermediates on Single Atom Alloy Catalysts
}

Matthew T. Darby ${ }^{a}$, Romain Reocreux ${ }^{a}$, E. Charles. H. Sykes ${ }^{b}$, Angelos Michaelides $^{c}$ and Michail Stamatakis ${ }^{a, *}$

a Thomas Young Centre and Department of Chemical Engineering, University College London, Roberts Building, Torrington Place, London, WC1E 7JE, United Kingdom b Department of Chemistry, Tufts University, 62 Talbot Ave., Medford, Massachusetts 02155, United States.

c Thomas Young Centre, London Centre for Nanotechnology and Department of Physics and Astronomy, University College London, Gower Street, London WC1E 6BT, United Kingdom

\footnotetext{
* Corresponding author; e-mail: $\underline{\text { m.stamatakis@ucl.ac.uk }}$
} 


\section{Abstract}

Doping isolated single atoms of a platinum group metal into the surface of a noble metal host is sufficient to dramatically improve the activity of the unreactive host yet also facilitates the retention of the host's high reaction selectivity in numerous catalytic reactions. The atomically dispersed highly active sites in these Single Atom Alloy (SAA) materials are capable of performing facile bond activations allowing for the uptake of species onto the surface, and the subsequent spillover of adspecies onto the noble host material, where selective catalysis can be performed. For example, SAAs have been shown to activate $\mathrm{C}-\mathrm{H}$ bonds at low temperatures without coke formation, as well as selectively hydrogenating unsaturated hydrocarbons with excellent activity. However to date, only a small subset of SAAs has been synthesised experimentally and it is unclear which metallic combinations may best catalyse which chemical reactions. To shed light on this issue, we have performed a wide-spread screening study using density functional theory to elucidate the fundamental adsorptive and catalytic properties of 12 SAAs (Ni-, Pd-, Pt- and Rh-doped $\mathrm{Cu}(111), \mathrm{Ag}(111)$ and $\mathrm{Au}(111))$. We considered the interaction of these SAAs with a variety of adsorbates often found in catalysis, and computed reaction mechanisms for the activation of several catalytically relevant species $\left(\mathrm{H}_{2}, \mathrm{CH}_{4}, \mathrm{NH}_{3}, \mathrm{CH}_{3} \mathrm{OH}\right.$ and $\left.\mathrm{CO}_{2}\right)$ by SAAs. Finally, we discuss the applicability of thermochemical linear scaling and the Brønsted-Evans-Polanyi relationship to SAA systems, demonstrating that SAAs combine weak binding with low activation energies to give enhanced catalytic behaviour over their monometallic counterparts. This work will ultimately facilitate the discovery and development of SAAs, serving as a guide to experimentalists and theoreticians alike. 


\section{Introduction}

Binary metal alloys are known to exhibit unique catalytic behaviour that is often distinct from their monometallic parent metals. ${ }^{1-2}$ One could, for instance, choose to combine a widelyused catalytic metal, e.g. from the platinum group, with a more inert metal, e.g. from the group 11 noble metals, in order to improve the selectivity of the former and the activity of the latter $^{1-2}$ In fact, pioneering work by Sykes and co-workers has shown that highly dilute bimetallic alloys, where single atoms of a platinum group metal are dispersed in the surface layer of a noble metal host, are sufficient to dramatically enhance the activity of the host material whilst retaining excellent selectivity for numerous catalytic chemistries. ${ }^{3-10}$ These Single Atom Alloys (SAAs) typically consist of just $1 \%$ of the active metal such that the dopant is isolated within the surface layer of its noble metal host. ${ }^{11-15}$ This strategy allows for facile activation of species onto the surface through the atomically dispersed active sites and enables selective catalysis to occur on the surface, whereas the rate of reaction was previously adsorption limited on the singe noble metal. ${ }^{3-8}$

For example Pd- and Pt-doped SAAs are capable of performing low temperature hydrogen activation and of facilitating the subsequent spillover onto their noble metal hosts, where selective hydrogenation can take place. ${ }^{3-4,8,15-18}$ Additionally, Pt/Cu SAAs have shown high resistance to coke formation during $\mathrm{C}-\mathrm{H}$ activation and subsequent $\mathrm{C}-\mathrm{C}$ coupling reactions and can perform efficient dry dehydrogenation of alcohols to carbonyls..$^{5,9-10,19-20}$ SAAs offer strong resistance to catalytic poisoning by $\mathrm{CO}^{21-22}$; yet, as alluded to above, still retain the ability to catalyse numerous chemistries with high activity at low temperatures.

Thus, SAAs hold the potential to be superior catalysts compared to pure metals, offering excellent activity, selectivity and stability. However, the discovery of metal-metal combinations that exhibit these attributes, as well as determining applicable chemistries, remain non-trivial tasks. In the majority of cases, catalytic materials are discovered by trialand-error methods, though this is both costly and time-consuming. 
Within the last two decades, significant advances in computational hardware and software have facilitated the widespread screening of materials for chemical properties using ab initio calculations, for example with Density Functional Theory (DFT). Though significant strides have been made, DFT remains computationally expensive for large systems, thereby reducing its effectiveness in catalyst discovery. ${ }^{23-26}$ It comes as no surprise that significant effort has been expended in attempts to reduce this computational burden by developing simple, yet reliable descriptor-based models from a subset of DFT data. ${ }^{24-26}$

Two elegant descriptor-based models that are widely used are Thermochemical Linear Scaling (TCS) ${ }^{24-25,27}$ and the Brønsted-Evans-Polanyi relationship (BEP). ${ }^{28-38}$ TCS is based on the empirical observation that the adsorption energies of chemically similar species, e.g. two molecules that bond via the same atom, are linearly correlated with one another. ${ }^{24-25,27}$ Similarly, the BEP relationship suggests that the difference in the adsorption energies of reactant and product states in an elementary reaction are linearly correlated to the activation energy. ${ }^{31}$ Thus, by combining TCS and the BEP relationship, one could extract kinetic data for a reaction, based on the adsorption energy of just a few species (e.g. appropriately chosen adatoms), making descriptor-based models exceptionally powerful tools in catalyst design. ${ }^{26,37-41}$

In this article, we present a DFT-based study in which we have screened the reactivity of 12 SAAs consisting of Ni-, Pd-, Pt- and Rh-doped Cu, Ag and Au. We have performed calculations to determine the formation energies of an array of catalytically relevant molecular fragments, and have analysed the data to explore the validity of TCS relations on these surfaces. Additionally, we determine the elementary step for the activation of several simple chemical species that contain bonds of significant importance in catalysis, namely $\mathrm{H}$ $\mathrm{H}, \mathrm{C}-\mathrm{H}, \mathrm{N}-\mathrm{H}, \mathrm{O}-\mathrm{H}$ and $\mathrm{C}=\mathrm{O}$. We go on to study the BEP relationship as applied to SAAs, such that this work can be used to aid in the design of new materials for catalysis. 


\section{Computational Details}

Periodic plane wave DFT calculations were performed using the Vienna Ab Initio Simulation Package version 5.4.1. ${ }^{42-44}$ A plane-wave kinetic energy cut-off of $400 \mathrm{eV}$ was used for the valence electron expansion and the core electrons were accounted for using projector augmented wave (PAW) potentials. ${ }^{45-46}$ Methfessel-Paxton smearing was used with a smearing width of $0.1 \mathrm{eV}$. The non-local optB86b-vdW exchange-correlation functional was used, which is a revised version of the van der Waals density functional of Dion et al. ${ }^{47-50}$ Lattice constants for the bulk pure fcc metals were optimised (Table S1) and agree well with those reported in the literature. ${ }^{48} \mathrm{~A} p(3 \times 3)$ surface unit cell was used with five layers of metal atoms for all calculations, where the topmost four layers and all adsorbates were allowed to fully relax. For SAA calculations, one surface atom of the host metal was replaced by a single dopant atom (Figure 1), prior to relaxation; the surface dopant atom density is similar to that in experiment in high density regions that are still in the SAA regime $(\sim 10 \%) .{ }^{12}$ The $p(3 \times 3)$ unit cell is large enough to have dopant atoms as fifth nearest neighbours, thus suppressing short range ordering. A vacuum region of approximately $10 \AA$ was included in the supercell in the z-direction to prevent interaction between periodic images along this direction. The Brillouin zone was sampled with a gamma-centred $13 \times 13 \times 1$ MonkhorstPack k-point grid which was sufficiently dense to ensure a high level of convergence in the formation energy of all species considered. The Hellmann-Feynmann forces acting on all free atoms were optimised to below $0.01 \mathrm{eV} \cdot \AA^{-1}$. We ensured electronic self-consistency at each ionic step to a tolerance of $10^{-7} \mathrm{eV}$. The transition state energies were found using the climbing image nudged elastic band (CI-NEB) and dimer formalisms of Jónsson and Henkleman. ${ }^{51-52}$ Vibrational frequency calculations were performed using the finite displacement method with a step size of $0.02 \AA$, ensuring all transition states were first order saddle points. 


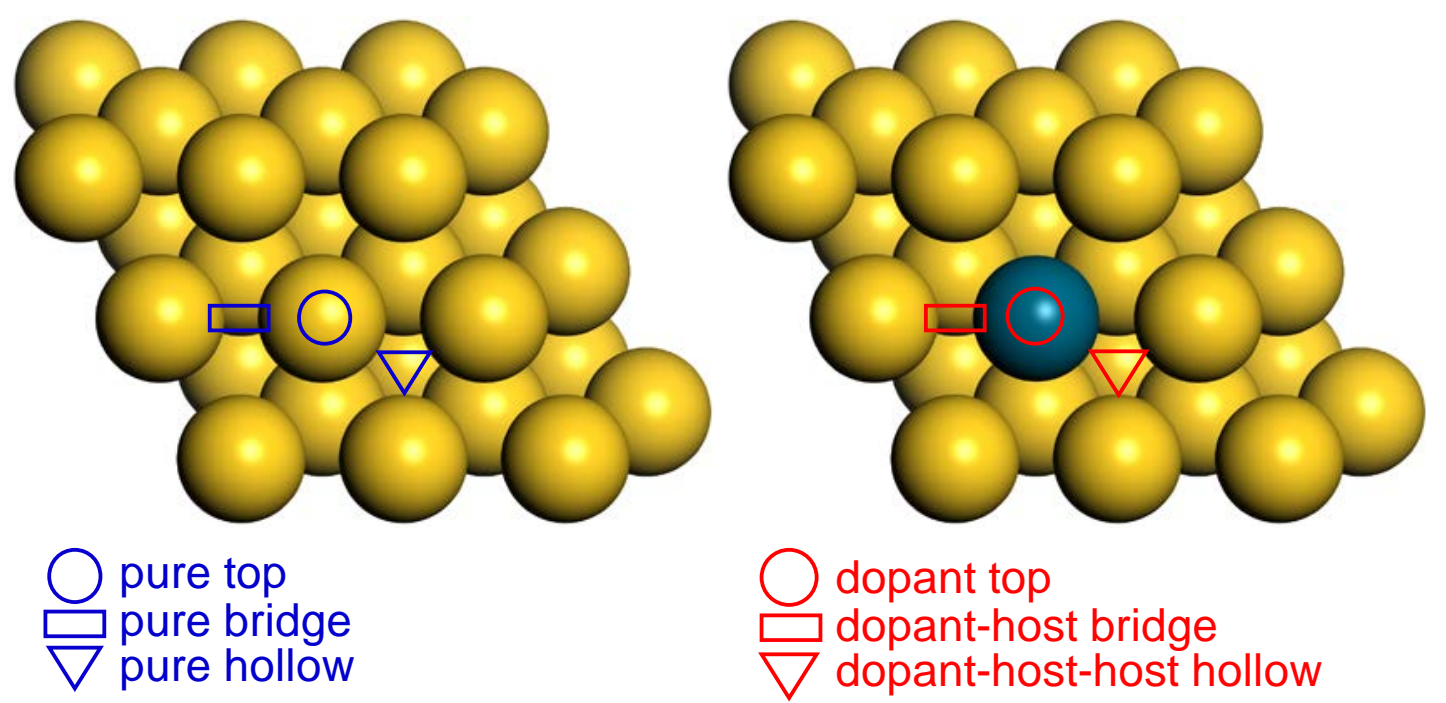

Figure 1: A typical pure metal fcc(111) surface (left, blue) and SAA fcc(111) surface (right, red). Top sites are marked by circles, bridge sites are marked by rectangles with the shorter edges marking the two contributing atoms and hollow sites are marked by triangles with the vertices marking the three contributing atoms. All calculations performed in this study utilise periodic DFT though just a single $\mathrm{p}(3 \times 3)$ cell is shown here for clarity.

\section{Energy Definitions}

\section{Formation Energy}

Given the large number of chemical species involved in this study, we define the formation energy of each adsorption system relative to a number of stable gas phase molecules $\left(\mathrm{H}_{2(\mathrm{~g})}\right.$, $\mathrm{CH}_{4(\mathrm{~g})}, \mathrm{NH}_{3(\mathrm{~g})}$, and $\left.\mathrm{CO}_{2(\mathrm{~g})}\right)$, thereby allowing the stability of different fragments to be compared to one another within the same reference. In the case of a generic adsorbate A, we give the formation energy $E_{f}$ as

$$
E_{f}(A)=E_{T o t}(M+A)-E_{T o t}(M)-E_{T o t}(G)
$$

where $E_{\text {Tot }}(M+A)$ is the DFT total energy of $A$ adsorbed on the metal slab $(\mathrm{M}), E_{\text {Tot }}(M)$ is the DFT total energy of clean $\mathrm{M}$ and $E_{\text {Tot }}(G)$ is a linear combination of gas phase DFT total energies whose atoms constitute A; e.g. for $\mathrm{A}=\mathrm{CO}, E_{T o t}(G)=\frac{1}{2} E_{T o t}\left(\mathrm{CO}_{2(g)}\right)+$ $\frac{1}{2} E_{\text {Tot }}\left(C_{4}\right)-E_{\text {Tot }}\left(H_{2}(g)\right)$ or for $\mathrm{A}=\mathrm{NH}_{2}, E_{\text {Tot }}(G)=E_{\text {Tot }}\left(N_{3}(g)\right)-\frac{1}{2} E_{\text {Tot }}\left(H_{2}(g)\right)$. We note that more negative values of $E_{f}$ imply higher stability of the adsorbed configurations they correspond to. 


\section{Activation and Reaction Energies}

The activation energy $E_{a}$ for a given chemical reaction is the difference in the DFT total

energy of the transition state $E_{T o t}^{T S}$ and the DFT total energy of the initial state of the reaction $E_{T o t}^{I S}$ where

$$
E_{a}=E_{T o t}^{T S}-E_{T o t}^{I S}
$$

The reaction energy $\Delta E_{R x n}$ is the difference in the DFT total energy between the final and initial states of the reaction, that is

$$
\Delta E_{R x n}=E_{T o t}^{F S}-E_{\text {Tot }}^{I S}
$$

Negative values of $\Delta E_{R x n}$ imply an exothermic reaction, whereas positive values imply an endothermic reaction. The "initial state" configurations of each reaction are physisorbed or chemisorbed precursor states and the "final state" configurations are the co-adsorbed dissociated products.

Having outlined our methodology, the rest of the paper is organised as follows: we present our data in the "Results and Discussion" section where we explore the interactions of a subset of catalytically relevant adsorbates with SAAs, comparing and contrasting the chemical properties of these surfaces with one another, as well as with their monometallic analogues. We further analyse the formation energy data in the context of TCS relations and determine the applicability thereof to SAA materials. Finally, we present calculations that elucidate the elementary pathways of simple bond dissociation reactions, which have catalytic application, and analyse this data in the context of the BEP relationship. The findings and conclusions drawn from our study will guide experimental and theoretical work that will advance the development of SAA materials within catalysis. 


\section{Results and Discussion \\ Adsorption on Single Atom Alloy Surfaces}

Our screening study involved the computation of adsorption geometries and energies of an assortment of catalytically relevant adspecies on SAA fcc(111) surfaces. These SAAs consist of inert coinage metal host materials $(\mathrm{Cu}, \mathrm{Ag}$ or $\mathrm{Au})$ doped with a single catalytically active surface metal atom ( $\mathrm{Ni}, \mathrm{Pd}, \mathrm{Pt}$ or $\mathrm{Rh}$ ). Our subset of adsorbates includes fragments such as atomic $\mathrm{C}, \mathrm{N}, \mathrm{O}$ and $\mathrm{H}$ as well as $\mathrm{CH}_{x}, \mathrm{NH}_{\mathrm{x}}, \mathrm{OH}_{\mathrm{x}}, \mathrm{CO}_{\mathrm{x}}$ and $\mathrm{MeOH}_{\mathrm{x}}$ where $0 \leq \mathrm{x} \leq 4,3$, 2, 2 and 1, respectively. We also perform calculations on monometallic analogues of each constituent of the SAAs for comparison.

A general observation from our calculations is that most of the fragments considered adsorb more strongly on the SAA surfaces than they do on the corresponding monometallic host materials but less strongly than they do on the surfaces of the pure metal surfaces of the dopant (Table S2). Thus, our subset of SAAs generally exhibit intermediate formation energies which is a result of the dilution of the more reactive metal atom into a less reactive host material surface. However, there are exceptions to this general observation. For example, Rh-doped and Ni-doped Au surfaces exhibit enhanced adsorption strength towards $\mathrm{CH}_{3} \mathrm{OH}$ and $\mathrm{NH}_{3}$ compared to pure $\mathrm{Rh}$ and $\mathrm{Ni}$, respectively (Table S2). Moreover, each alloy of $\mathrm{Rh}$ binds $\mathrm{CO}$ more strongly than pure $\mathrm{Rh}$, in a good agreement with our previous work where we used a similar computational setup, albeit with RPBE as the xc-functional. ${ }^{21}$ We also note that in some cases SAAs bind adsorbates more weakly than their corresponding noble metal hosts. This is particularly common for Pd- and Pt-doped $\mathrm{Cu}$. For the former, we compute more negative formation energies on pure $\mathrm{Cu}$ than this SAA for $\mathrm{N}, \mathrm{NH}, \mathrm{NH}_{2}, \mathrm{CH}_{3}$, $\mathrm{CH}_{3} \mathrm{OH}, \mathrm{O}$ and $\mathrm{H}_{2} \mathrm{O}$, whereas this is the case for $\mathrm{NH}, \mathrm{NH}_{2}, \mathrm{NH}_{3}, \mathrm{CH}_{3} \mathrm{OH}, \mathrm{O}$ and $\mathrm{H}_{2} \mathrm{O}$ on the latter (Table S2).

Interestingly, despite marked differences in the reactivity between the host metal and dopant metal, the favoured adsorption sites for most adsorbates on SAAs tend to follow simple valency rules that are also adhered to by most pure metal surfaces ${ }^{53}$ That is, closed-shell 
Lewis bases, as well as those species with a single dangling bond prefer to adsorb on the dopant atom top site (Figure 1). Fragments with two or three dangling bonds are most stable on shared dopant-host bridge and dopant-host-host hollow sites (Figure 1), respectively. Similarly, single adatom adsorption is preferable in dopant-host-host hollow sites (Figure 1) on all SAAs, with the exceptions of $\mathrm{H}$ adsorption on $\mathrm{Pt} / \mathrm{Ag}(111)$ and $\mathrm{Pt} / \mathrm{Au}(111)$. In these cases, $\mathrm{H}$ is unstable in Pt-host-host hollow sites and unconstrained geometric minimisation from such a configuration results in $\mathrm{H}$ relaxing to the $\mathrm{Pt}$ top site (notably on pure $\mathrm{Pt}(111), \mathrm{H}$ is also more stable on the Pt top site than in high-symmetry sites).

\section{Thermochemical Scaling Relations}

To aid in the rational design and discovery of new catalytic materials, one can employ TCS. Extrapolation of linear relationships given by TCS can yield approximate formation energies of complex fragments allowing for inferences to be made about the reactivity of a catalytic surface with little computational expense. Thus, in this section we evaluate the applicability of TCS to SAA adsorption systems, though in order to compare and contrast to the analogous pure metal relations we begin by discussing the TCS thereon.

\section{Pure Metal Surfaces}

On pure metal surfaces, it is well established that the adsorption energies of a multitude of molecular fragments scale linearly with that of other chemically similar fragments. ${ }^{24-25,27} \mathrm{We}$ show on our subset of monometallic fcc(111) surfaces, that this is true (Figure 2, Table S3). Our data shows that there are strong linear correlations between the formation energies of $C$ adatoms and $\mathrm{CH}_{x}, \mathrm{CH}_{3} \mathrm{OH}, \mathrm{CO}$ and $\mathrm{H}$ fragments (Figure 2, Table S3), indicating that changes in the formation energy of any of these fragments will be accompanied by a change in that of others that can be predicted by the linear relation. Similarly, $\mathrm{N}$ adatom formation energies are strongly correlated to $\mathrm{NH}_{\mathrm{x}}, \mathrm{CO}$ and $\mathrm{H}$ fragments (Figure 2, Table S3). For most fragments related to $\mathrm{O}$ adatoms in this study, the TCS correlations are weak, though reasonable linear correlations between the formation energy of $\mathrm{O}$ and that of $\mathrm{OH}$ and $\mathrm{H}$ exist, in addition to a strong correlation with $\mathrm{CH}_{3} \mathrm{O}$ (Figure 2, Table S3). 
Comparisons between the formation energies of closed shell fragments with lone pairs of electrons that are explored in this study, show that these are all strongly correlated to one another (Figure 2, Table S3). That is the formation energies of $\mathrm{CO}, \mathrm{H}_{2} \mathrm{O}, \mathrm{CH}_{3} \mathrm{OH}$ and $\mathrm{NH}_{3}$ on pure metal (111) surfaces all exhibit strong TCS relations. The case of CO is of particular interest here: the formation energies of this species on pure metals scale with the formation energies of all of these fragments in addition to those of $\mathrm{C}, \mathrm{N}$ and $\mathrm{H}$ adatoms. This implies that surfaces that generally bind these species more strongly are also more susceptible to poisoning by $\mathrm{CO}$.

Though just a few examples have been shown here, there is wide applicability of TCS on pure metallic surfaces with many more adsorption systems obeying these linear scaling relations. ${ }^{24-25}$ This allows us to make inferences about the applicability of a metal catalyst to a given chemical system and about its potential performance. Having briefly discussed our findings on pure metal systems, which are corroborated by the findings of others ${ }^{24-25,27,54-56}$, we now move on to discuss the corresponding TCS relations on SAAs.

\section{Single Atom Alloy Surfaces}

As we have discussed already, SAAs have an increased chemical heterogeneity in their surface layer compared to their monometallic counterparts. SAAs have an isolated dopant atom that gives rise to the formation of several distinct surface adsorption sites (Figure 1) that vary in their bonding contributions from each metal alloy constituent. We have already suggested that despite the marked difference in reactivity of each metal, adsorbates on SAAs generally follow the same valency rules found on their pure metal analogues. ${ }^{53}$

To assess the consequences of SAA surface chemical heterogeneity on TCS, we begin by considering the correlation between the formation energy of a single adatom on shared dopant-host-host hollow sites and that on dopant-only top sites (Figure 2). Interestingly we find that there is no correlation between these two quantities for $\mathrm{C}, \mathrm{N}$ and $\mathrm{O}$ adatoms, whereas on pure metal surfaces, hollow site to top site formation energies of these adatoms 
are very strongly correlated (Figure 2). This demonstrates that the adsorption behaviour at a SAA dopant top site is distinct from that of shared dopant and host sites and therefore formation energies of different fragments may be decoupled.

Thirumalai and Kitchin ${ }^{57}$ recently explored the electronic structure of SAA surfaces. They found that the atom-projected density of states of the dopant in SAAs has a sharp feature close to the Fermi level that is akin to that of a single gas phase dopant atom. This peak is thought to be the result of ineffective mixing of the electron densities between the dopant and host materials, resulting in SAAs exhibiting unique reactivity that is distinct from traditional transition metals and their alloys. ${ }^{57}$ Such ineffective mixing of transition and noble metal electron densities is also described in a publication by Inderwildi et al..$^{58}$ on $\mathrm{Rh} / \mathrm{Ag}$ bimetallic alloys. In this instance, they calculated a higher number of occupied Rh d-states close to the Fermi level for alloys with an increased Ag molar fraction; this can be attributed to poor mixing between the d-states of each metal in the alloy..$^{58-59}$ In the context of our calculations, poor charge mixing between the transition metal and the noble metal suggests that the isolated dopant top site will have distinct reactivity from shared dopant-host and dopant-host-host sites as we have observed in Figure 2. 

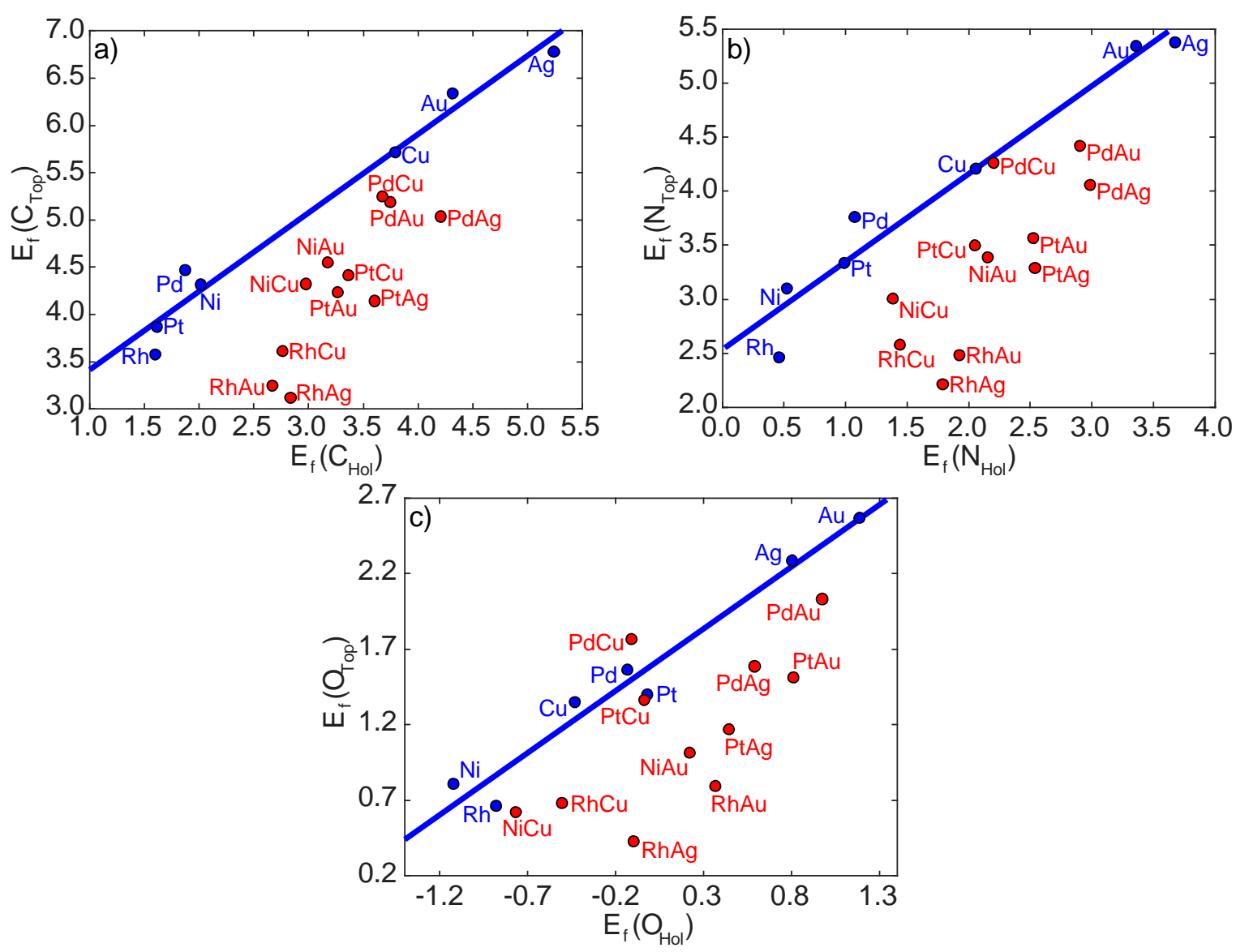

Figure 2: Thermo-chemical linear scaling plots of the formation energy, $\mathrm{Ef}$, of a single adatom, A, adsorbed on the top site (dopant top site on SAAs) as function of that of the same adatom on a hollow site (shared dopant-host-host on SAAs) for the cases of a) $A=C, b) A=N$ and $c$ ) $A=O$. Pure metal data points are given in blue, whereas those of SAAs are shown in red. Trendlines are plotted for the pure metals (blue) though are not included for SAAs due to the poor correlation of the data.

Considering a set of molecular species we find that for SAA surfaces, pure metal TCS relations hold remarkably well in the majority of cases. The formation energies of single adatoms bound to the more favoured shared dopant-host-host hollow sites, scale well with those of other fragments adsorbed at shared site types. For example, C adatom formation energies scale well with the formation energies of $\mathrm{CH}$ and $\mathrm{CH}_{2}$ species (Figure 3). Similarly the formation energies of $\mathrm{N}$ adatoms scale well with those of $\mathrm{NH}$ and $\mathrm{NH}_{2}$ fragments and $\mathrm{O}$ adatom formation energies scale well with that of $\mathrm{OH}$ (Figure 3). Notably, the adsorption of $\mathrm{OH}$ on SAAs is typically at the shared dopant-host-host site, though in the cases of $\mathrm{Pt} / \mathrm{Au}(111)$ and $\mathrm{Rh} / \mathrm{Au}(111)$ dopant top site adsorption is more favourable. 

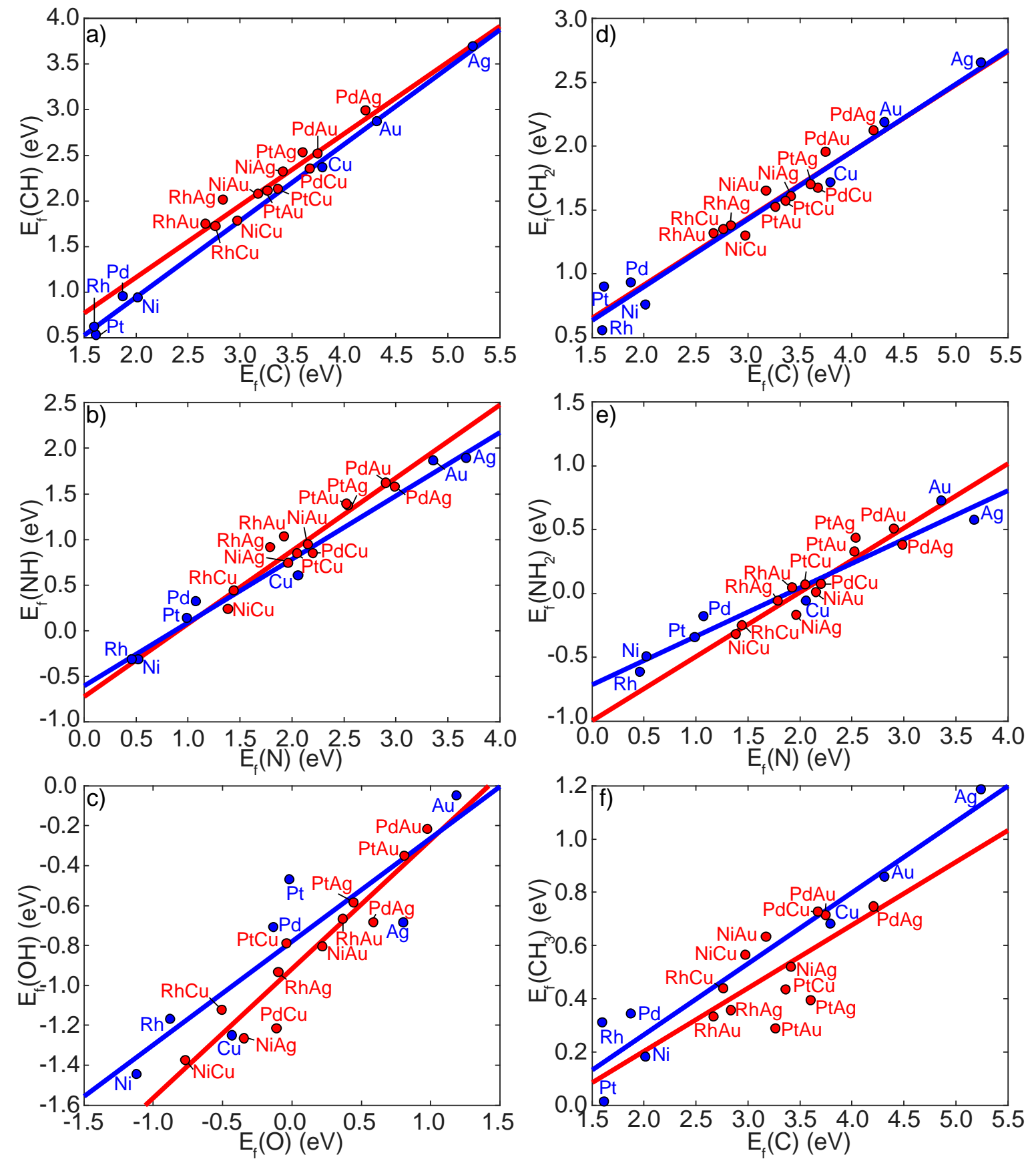

Figure 3: Thermo-chemical linear scaling relations of the formation energy Ef corresponding to fragments bound in the most stable adsorption site on pure metals (blue) and SAAs (red) for a) $\mathrm{CH}$ vs. C; b) $\mathrm{NH}$ vs. $\mathrm{N}$; c) $\mathrm{OH}$ vs. $\mathrm{O}$; d) $\mathrm{CH}_{2}$ vs. $\mathrm{C}$ e) $\mathrm{NH}_{2}$ vs. $\mathrm{N}$; and f) $\mathrm{CH}_{3}$ vs. C. Corresponding linear regression fitting parameters and error analysis are given in the supporting information.

Our calculations show that the formation energies of $\mathrm{C}, \mathrm{N}$ and $\mathrm{O}$ based fragments that preferentially (or solely) adsorb to the dopant top site instead of shared sites do not scale as well with the formation energies of the aforementioned adatoms. For example, let us consider $\mathrm{CH}_{\mathrm{x}}$ fragment adsorption. In this case, $\mathrm{C}$ and $\mathrm{CH}$ preferentially bind to shared 
dopant-host-host hollow sites and as a result, their formation energies are very strongly correlated $\left(\mathrm{SAA} \mathrm{R} \mathrm{R}^{2}=0.926\right.$, pure metal $\left.\mathrm{R}^{2}=0.997\right)$. On the other hand, $\mathrm{CH}_{2}$ fragments are most stable when bound to shared dopant-host bridge sites, and thus have a different relative contribution to their bonding from each metal type. Thus, the strength of the correlation between the $\mathrm{C}$ and $\mathrm{CH}_{2}$ formation energies is slightly lower (SAA $\mathrm{R}^{2}=0.888$, pure metal $\left.\mathrm{R}^{2}=0.971\right)$. Finally, when considering the $\mathrm{CH}_{3}$ fragment, which adsorbs most favourably to the SAA top site, the $\mathrm{C}$ and $\mathrm{CH}_{3}$ formation energies are poorly correlated (SAA $\mathrm{R}^{2}=0.443$, pure metal $\mathrm{R}^{2}=0.928$ ). In this case, the bonding contribution between $\mathrm{CH}_{3}$ and the SAA surface is primarily from the dopant metal atom.

The remaining fragments in our study that adsorb preferentially to SAA top sites are Lewis bases and formally bond via a lone pair of electrons to each surface. Interestingly, we find that strong linear correlations between the formation energies of $\mathrm{CH}_{3} \mathrm{OH}, \mathrm{NH}_{3}$ and $\mathrm{H}_{2} \mathrm{O}$ on SAAs exist (Table S3). The TCS relation between $\mathrm{CH}_{3} \mathrm{OH}$ and $\mathrm{C}$ is weak on SAAs $\left(\mathrm{R}^{2}=\right.$ 0.443) though much stronger on the pure metal surfaces $\left(\mathrm{R}^{2}=0.971\right)$, as is the case for $\mathrm{NH}_{3}$ and $N\left(S A A R^{2}=0.183\right.$, pure metal $\left.R^{2}=0.811\right)$. Finally, in the case of $C O$ we find that, despite also binding to the dopant top site, the formation energies of CO on SAAs are uncorrelated to those of $\mathrm{H}_{2} \mathrm{O}, \mathrm{CH}_{3} \mathrm{OH}$ and $\mathrm{NH}_{3}$, which is in contrast to the pure metal surfaces. However, the formation energy of $\mathrm{CO}$ is correlated to that of $\mathrm{C}$, though on SAAs this TCS relation is distinct from that of the pure metals, with the binding strength of $\mathrm{CO}$ on SAAs falling significantly with small decreases in that of $C$ compared to the pure metals (Table S3).

As we have discussed already, those adsorbates that bond primarily through accepting electron density from the surface (e.g. open-shell fragments) have formation energies that scale well with one another, providing they are bound to the same SAA surface site. A similar argument holds for those that primarily donate density to the surface (i.e. closed-shell Lewis base fragments). However, the formation energies of density acceptors and those of density donors that bind to the same SAA surface site are non-correlated. The TCS for 
donor adsorbates depends on the ability of each surface to accept electron density rather than the ability of the adsorbate to donate it; the surface accepting properties remain constant, irrespective of the adsorbate and so donor species formation energies are correlated with one another. In this sense, $\mathrm{CO}$ is unique. $\mathrm{CO}$ both accepts and donates density to the surface thanks to synergic bonding. Thus, it is no surprise that CO formation energies are non-correlated with those of the traditional Lewis bases due to its distinct bonding mode. $\mathrm{CO}$ is often used as a probe molecule for general reactivity in surface science experiments, though it may not be widely applicable for SAAs as its adsorption properties do not scale well with all fragments. Moreover, a lack of correlation between the adsorption strengths of $\mathrm{CO}$ and other fragments implies that SAAs could resist CO poisoning in some cases, as we have shown in previous publications..$^{21-22}$

So far we have discussed the adsorption behaviour of SAAs towards a set of adsorbates that are typically found in an array of catalytic processes. We have shown that the preferred surface sites types for adsorption on SAAs are generally given by site valency rules ${ }^{53}$, which in turn lead us to examine the applicability of TCS relations on these surfaces. In the next section we present calculations pertaining to the elucidation of molecular mechanisms for several simple, yet catalytically relevant bond dissociation reactions on SAAs. We discuss how the kinetics of these reactions differ from that on pure metal surfaces, and we highlight interesting cases, comparing to experimental data and discussing the appropriateness of universal BEP relationships in describing these chemistries on SAAs.

\section{Catalytically Relevant Bond Dissociation Reactions}

In this section, we explore the chemistries and bond dissociations of several simple, yet catalytically relevant compounds on SAA surfaces. Our study has focussed on $\mathrm{H}-\mathrm{H}, \mathrm{C}-\mathrm{H}, \mathrm{N}-$ $\mathrm{H}, \mathrm{O}-\mathrm{H}$ and $\mathrm{C}=\mathrm{O}$ bond activations from $\mathrm{H}_{2}, \mathrm{CH}_{4}, \mathrm{NH}_{3}, \mathrm{CH}_{3} \mathrm{OH}$ and $\mathrm{CO}_{2}$, respectively. By computing the minimum energy pathways for these bond dissociations, we have found that whilst exhibiting intermediate adsorption properties, SAAs also exhibit low activation energies (see supporting information Table S4). Thus, we proceed from here to discuss the 
catalysis of these bond scissions on SAAs, alluding to their mechanistic pathways whilst making comparisons with the pure metals. We link our calculations to previous experiments, showing that our data is in strong agreement with these works. Moreover, we highlight a selection of systems that look extremely promising in experimental/practical applications and elucidate BEP relationships for our set of reactions on SAAs.

\section{Hydrogen Dissociation}

As we showed in the "Adsorption on Single Atom Alloy Surfaces" section, shared dopanthost-host hollow sites are the most favoured for dissociated $\mathrm{H}$ adatoms on most SAAs. For molecular $\mathrm{H}_{2}$, we have found that there is a stable adsorption site on the dopant atom top site (Figure 4). This binding is a weak physisorption that we are able to capture as a result of using a dispersion-inclusive xc-functional (OptB86b-vdW). The physisorption of $\mathrm{H}_{2}$ is nonactivated and serves as a precursor state for $\mathrm{H}-\mathrm{H}$ dissociation on all SAAs. This behaviour is similar to pure $\mathrm{Ni}(111), \mathrm{Pd}(111), \mathrm{Pt}(111)$ and $\mathrm{Rh}(111)$, which all facilitate the stable physisorption of molecular $\mathrm{H}_{2}$ as a precursor state for $\mathrm{H}-\mathrm{H}$ scission.

The mechanism for $\mathrm{H}_{2}$ activation over $\mathrm{SAA}(111)$ surfaces proceeds from the precursor initial state via a top-bound transition state (Figure 4). For the majority of SAAs, the final dissociated $\mathrm{H}$ adatoms (Figure 4) are bound to shared dopant-host-host hollow sites (Pt/Ag(111) and Pt/Au(111) are exceptions as H preferentially adsorbs to top dopant sites and so the final state consists of one top $\mathrm{H}$ and one hollow $\mathrm{H}$ ).

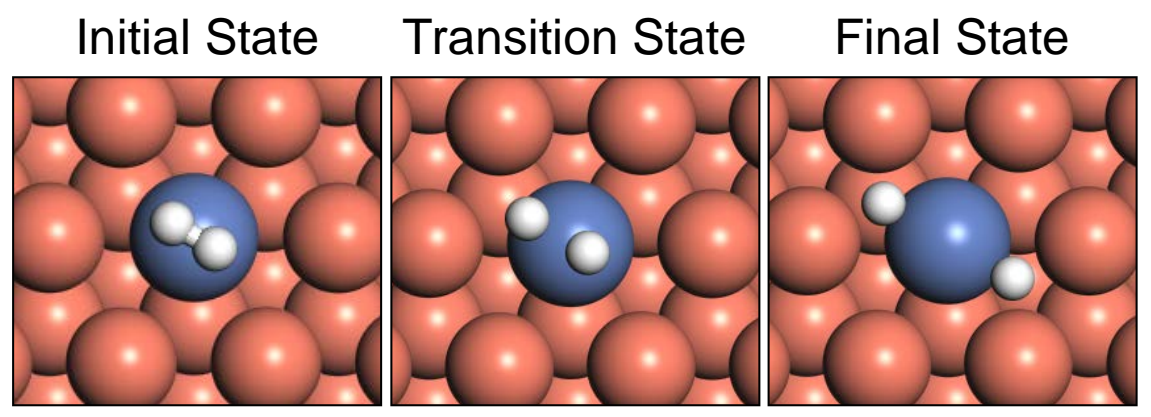

Figure 4: The initial state (left), transition state (middle) and final state (right) for $\mathrm{H}_{2}$ dissociation on $\mathrm{Ni} / \mathrm{Cu}(111) \mathrm{SAA}$. A five layer slab was used in these calculations along with a $\mathrm{p}(3 \times 3)$ unit cell. Only a portion of the cell is shown for clarity. 
As the transition state is bound to the top site of the dopant atom, there is significant stabilisation of this state that is comparable in many cases to that of the pure dopant metals. Consistently, we calculate low activation energies for $\mathrm{H}-\mathrm{H}$ bond dissociation on SAAs (Table S4). For example, the Pt-doped SAAs exhibit $\mathrm{H}_{2}$ activation barriers of $\leq 0.02 \mathrm{eV}$. Similarly, Rh-doped SAAs can catalyse $\mathrm{H}-\mathrm{H}$ scission with activation energies of $\leq 0.08 \mathrm{eV}$ and for $\mathrm{Ni}$ doped $\mathrm{Cu}(111)$ SAAs this barrier is just $0.13 \mathrm{eV}$. Considering the pure host and dopant materials, our calculations show the $\mathrm{H}-\mathrm{H}$ activation barriers to be significantly higher and comparable to those of the SAAs respectively. The $\mathrm{H}-\mathrm{H}$ scission kinetic barriers on $\mathrm{Ag}(111)$, $\mathrm{Au}(111)$ and $\mathrm{Cu}(111)$ are $1.10 \mathrm{eV}, 1.04 \mathrm{eV}$ and $0.42 \mathrm{eV}$, respectively, whereas on $\mathrm{Ni}(111)$, $\mathrm{Pd}(111), \mathrm{Pt}(111)$ and $\mathrm{Rh}(111)$, these are $0.07 \mathrm{eV}, 0.04 \mathrm{eV}, 0.01 \mathrm{eV}$ and $0.02 \mathrm{eV}$, respectively. Thus, for $\mathrm{H}_{2}$ activation on SAAs, the barriers to dissociation are notably more dopant-like than host-like.

Extended solid surfaces and nanoparticle catalysts of Pd- and Pt-doped Cu SAAs, as well as $\mathrm{Pd}$-doped Au have been shown to perform facile, low temperature $\mathrm{H}_{2}$ activation and highly selective hydrogenation catalysis. ${ }^{3-4,6,8,15-18,22}$ The dissociation of $\mathrm{H}_{2}$ is often the rate limiting step in hydrogenation reactions on pure $\mathrm{Cu}, \mathrm{Ag}$ and $\mathrm{Au}$. On the other hand, pure $\mathrm{Ni}, \mathrm{Pd}, \mathrm{Pt}$ and Rh can easily activate hydrogen, though suffer from poor selectivity towards hydrogenated products. Fermi-Dirac statistics can be used to show that entropic effects arising from the high number of less active sites (host metal atoms) in a SAA promote $\mathrm{H}$ adatom spillover from the dopant to host regions (see supporting information), allowing these adatoms to participate in hydrogenation reactions. Thus, in addition to the ability to readily activate hydrogen thanks to the isolated dopant atom, SAAs exhibit excellent reaction selectivity that is comparable to the pure group 11 metals as a result of spillover. We have previously observed several instances of this using a combination of STM, TPD and reactor studies on $\mathrm{Pd} / \mathrm{Cu}, \mathrm{Pt} / \mathrm{Cu}$ and Pd/Au SAAs. ${ }^{3-4,}$ 6, 8, 15-18, 22 


\section{Methane Activation}

Similar to the adsorption of molecular $\mathrm{H}_{2}, \mathrm{CH}_{4}$ physisorbs to the top site of all SAAs (Figure 5). Using a dispersion-inclusive functional, we are able to capture the energetics of this interaction well. ${ }^{60-61}$ In general, the physisorption of $\mathrm{CH}_{4}$, mainly attributed to van der Waals interactions, is somewhat independent of the metal surface. Thus, $\mathrm{CH}_{4}$ has an formation energy of approximately $-0.2 \mathrm{eV}$ on most surfaces. The $\mathrm{C}-\mathrm{H}$ bond activation in $\mathrm{CH}_{4}$ occurs over the dopant top site on each SAA with the dissociating $\mathrm{C}-\mathrm{H}$ bond vector orientated towards either a dopant-host bridge site of dopant-host-host hollow site depending on the surface (Figure 5). In all cases, the dissociated $\mathrm{H}$ adatom moves into a shared dopant-hosthost hollow site and the $\mathrm{CH}_{3}$ fragment remains formally on the dopant top site, though is displaced from the high symmetry position due to a lateral interaction with $\mathrm{H}$ (Figure 5). As noted earlier, $\mathrm{CH}_{3}$ in the absence of $\mathrm{H}$ is stable only on the dopant top site of SAAs.

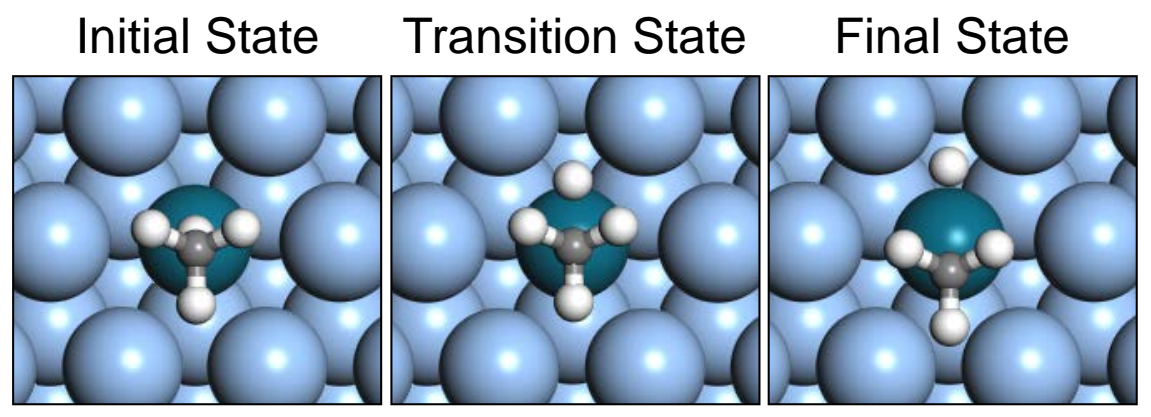

Figure 5: The initial state (left), transition state (middle) and final state (right) for $\mathrm{CH}_{4}$ dissociation on $\mathrm{Pt} / \mathrm{Ag}(111)$ SAA. A five layer slab was used in these calculations along with a $\mathrm{p}(3 \times 3)$ unit cell. Only a portion of the cell is shown for clarity.

As in the case of $\mathrm{H}_{2}$ dissociation, the SAAs have notable effects on the activation energies (Table S4) of the $\mathrm{C}-\mathrm{H}$ bond dissociation reactions due to the location of the transition state. The transition state for $\mathrm{C}-\mathrm{H}$ activation is located on the dopant top site, where it is stabilised by the more reactive dopant metal atom, thereby lowering the barrier to $\mathrm{C}-\mathrm{H}$ dissociation significantly compared to the pure host metal case. In particular, $\mathrm{Ag}(111), \mathrm{Au}(111)$ and $\mathrm{Cu}(111)$ have $\mathrm{C}-\mathrm{H}$ activation barriers of $2.11 \mathrm{eV}, 1.78 \mathrm{eV}$ and $1.48 \mathrm{eV}$, respectively, whereas 
the barriers we calculate for $\mathrm{C}-\mathrm{H}$ bond scission on SAAs, are comparable to those for pure $\mathrm{Pd}(111)(0.68 \mathrm{eV}$ ) and pure $\mathrm{Ni}(111)(0.75 \mathrm{eV})$. For example, Ni-doped $\mathrm{Ag}(111)$ and $\mathrm{Cu}(111)$ both have $\mathrm{C}-\mathrm{H}$ activation energies of $0.82 \mathrm{eV}$ whereas Pt-doped $\mathrm{Ag}(111), \mathrm{Au}(111)$ and $\mathrm{Cu}(111)$ have values of $0.94 \mathrm{eV}, 0.85 \mathrm{eV}$ and $0.92 \mathrm{eV}$, respectively. Even lower barriers are exhibited by Rh -doped SAAs, all of which have $\mathrm{C}-\mathrm{H}$ scission barriers that are very similar to that of pure $\mathrm{Rh}(111)$ (0.56 eV). In particular, Rh-doped $\mathrm{Ag}(111), \mathrm{Au}(111)$ and $\mathrm{Cu}(111)$ have values of $0.55 \mathrm{eV}, 0.61 \mathrm{eV}$ and $0.64 \mathrm{eV}$, respectively.

The low activation energies exhibited for $\mathrm{CH}_{4}$ activation by the dopant atom of SAAs allow for the activation of $\mathrm{CH}_{x}$ species onto the SAA surface. The high multiplicity of host metal sites and the isolation of single dopant atoms will facilitate the entropic spillover of activated $\mathrm{CH}_{\mathrm{x}}$ fragments onto facets of the host material where coupling can occur (see supporting information). In fact, we have recently shown that Pt/Cu SAA extended surfaces and nanoparticles are capable of performing low temperature $\mathrm{C}-\mathrm{H}$ bond scission, though do not coke as a result of $\mathrm{Cu}$-like $\mathrm{C}$ - $\mathrm{H}$ activation barriers for low valency $\mathrm{CH}_{\mathrm{x}}$ fragments, ${ }^{5}$ or due to $\mathrm{C}-\mathrm{C}$ coupling reactions proceeding with low barriers on the $\mathrm{Cu}$ host material. ${ }^{62}$ On each of the pure host materials we consider here, the coupling of carbonaceous fragments to produce higher order hydrocarbons is rate limited by the scission of $\mathrm{C}-\mathrm{H}$ bonds. ${ }^{62-65}$ Conversely, the pure dopant metal surfaces can readily activate $\mathrm{C}-\mathrm{H}$ bonds though suffer from poor selectivity and coke formation. ${ }^{5}$ Using SAAs, one can activate the necessary $\mathrm{C}-\mathrm{H}$ bonds to create $\mathrm{CH}_{x}$ fragments that can be coupled on pure host regions of the alloy, making SAAs a highly attractive prospect for the upgrade of shale gas.

\section{Ammonia Activation}

The chemisorption $\mathrm{NH}_{3}$ is strong on all SAA surfaces and, as discussed earlier, the only stable adsorption site local to the dopant metal atom is the dopant top site (Figure 6). The $\mathrm{N}-\mathrm{H}$ bond scission transition state is located on the dopant top site, where the dissociating $\mathrm{NH}_{2}$ fragment is positioned towards a shared dopant-host bridge and the dissociating $\mathrm{H}$ 
fragment is approximately orientated towards the bridge with an $\mathrm{NH}_{2}$-dopant- $\mathrm{H}$ angle of $180^{\circ}$

(Figure 6). On all of the SAAs, the dissociated $\mathrm{NH}_{2}$ fragment relaxes onto the shared dopant-host bridge site (Figure 6), thereby satisfying site valency rules. In the majority of cases, the dissociated $\mathrm{H}$ adatom relaxes into a shared dopant-host-host hollow site that is $150^{\circ}$ about the dopant from the dissociated $\mathrm{NH}_{2}$ fragment (Figure 6). In the cases of $\mathrm{Au}(111)$ based SAAs this $\mathrm{H}$ relaxation is to the shared dopant-host bridge sites at $180^{\circ}$ about the dopant relative to $\mathrm{NH}_{2}$.

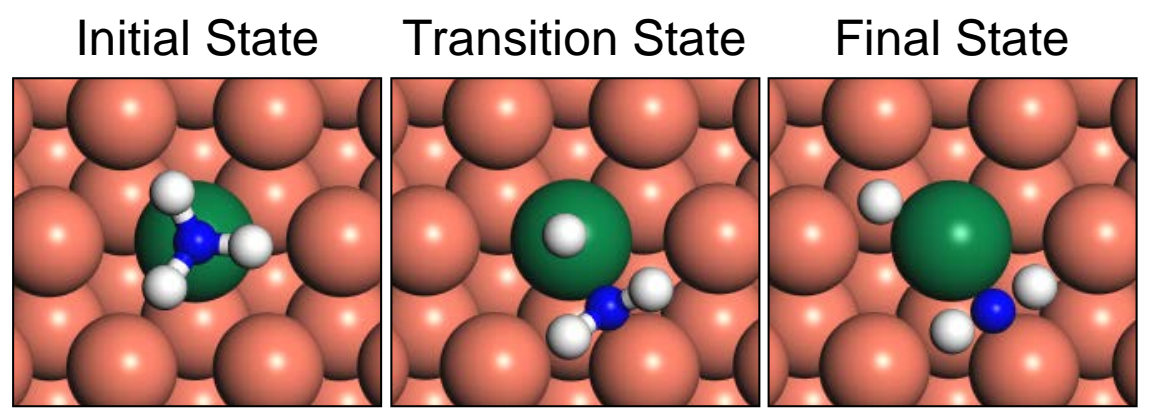

Figure 6: The initial state (left), transition state (middle) and final state (right) for $\mathrm{NH}_{3}$ dissociation on $\mathrm{Rh} / \mathrm{Cu}(111) \mathrm{SAA}$. A five layer slab was used in these calculations along with a $\mathrm{p}(3 \times 3)$ unit cell. Only a portion of the cell is shown for clarity.

Similarly to the $\mathrm{H}_{2}$ and $\mathrm{CH}_{4}$ cases discussed so far, as the transition states for $\mathrm{N}-\mathrm{H}$ dissociation on SAAs are located over the single dopant atom, there is significant stabilisation of this transition state compared to the pure host metal cases. Consequently, our calculations suggest that $\mathrm{N}-\mathrm{H}$ bond scission on SAAs exhibits significantly lower kinetic barriers (Table S4) than on pure $\mathrm{Ag}(111), \mathrm{Au}(111)$ and $\mathrm{Cu}(111)$ with barriers of $2.16 \mathrm{eV}$, $2.15 \mathrm{eV}$ and $1.69 \mathrm{eV}$, respectively. $\mathrm{NH}_{3}$ can be activated with relatively lower activation barriers of $1.21 \mathrm{eV}, 1.49 \mathrm{eV}, 1.27 \mathrm{eV}$ and $1.32 \mathrm{eV}$ on Ni(111), $\mathrm{Pd}(111), \mathrm{Pt}(111)$ and $\mathrm{Rh}(111)$. Ni-doped $\mathrm{Ag}(111)$ and $\mathrm{Cu}(111)$ SAAs exhibit $\mathrm{NH}_{3}$ activation energies (1.32 eV and $1.26 \mathrm{eV}$, respectively) that are comparable to pure $\mathrm{Ni}(111)$, though the $\mathrm{Ni} / \mathrm{Au}(111)$ SAA has a notably higher barrier of $1.72 \mathrm{eV}$. Similarly with the other SAA combinations, regardless of the dopant atom, SAAs with $\mathrm{Au}$ as the host metal exhibit much higher $\mathrm{N}-\mathrm{H}$ activation energies than their $\mathrm{Ag}(111)$ and $\mathrm{Cu}(111)$ analogues. For example, Pd-, Pt- and Rh-doped $\mathrm{Au}(111)$ 
have $\mathrm{N}-\mathrm{H}$ scission barriers of $2.00 \mathrm{eV}, 1.91 \mathrm{eV}$ and $1.72 \mathrm{eV}$ respectively, whereas those metals doped in $\mathrm{Ag}(111)$ have corresponding activation energies of $1.67 \mathrm{eV}, 1.54 \mathrm{eV}$ and $1.31 \mathrm{eV}$, and those doped in $\mathrm{Cu}(111)$ values of $1.57 \mathrm{eV}, 1.46 \mathrm{eV}$ and $1.33 \mathrm{eV}$.

Our calculations suggest that the activation barriers for SAAs with $\mathrm{Ag}(111)$ and $\mathrm{Cu}(111)$ hosts are more dopant-like, whereas those with $\mathrm{Au}(111)$ hosts are more host-like. Thus, in choosing a SAA material to perform $\mathrm{N}-\mathrm{H}$ bond catalysis, one should select a SAA with a $\mathrm{Ag}(111)$ or $\mathrm{Cu}(111)$ for the best activity. However, it is also of interest to note that, as discussed earlier, SAAs with $\mathrm{Au}(111)$ hosts are capable of performing facile $\mathrm{C}-\mathrm{H}$ bond dissociations (as well as $\mathrm{O}-\mathrm{H}$ activation as we will discuss shortly) and therefore may offer enhanced selectivity (compared to pure metals) towards these bond scissions without activating $\mathrm{N}-\mathrm{H}$ bonds, for example in amines.

We should note that the $\mathrm{NH}_{3}$ activation mechanisms we have calculated here are all for flat fcc(111) surfaces which are known known to have generally low activity for catalysing such a reaction; hence the large activation energies we obtained. Stepped surfaces such as fcc(211) are much more active. Still though, there exist linear relationships between the activation energies on surfaces with different coordination numbers, as noted in the literature ${ }^{66}$; it is therefore suggestive that the trends we calculate across the fcc(111) surfaces will also be valid on other non-flat facets.

\section{Methanol Dissociation}

The chemisorption of $\mathrm{CH}_{3} \mathrm{OH}$ involves dative bonding via $\mathrm{O}$ to the dopant metal top sites on each SAA surface, with the $\mathrm{O}-\mathrm{H}$ bond nearly parallel to the surface plane in each case (Figure 7, top), in good agreement with earlier work. ${ }^{67}$ One exception is on $\mathrm{Pt} / \mathrm{Cu}(111)$, on which it is more favourable for $\mathrm{CH}_{3} \mathrm{OH}$ to adsorb to an adjacent $\mathrm{Cu}$ atom rather than the single dopant atom (Figure 7, bottom), in good agreement with calculations of $\mathrm{CH}_{3} \mathrm{CH}_{2} \mathrm{OH}$ on this SAA. ${ }^{19}$ Interestingly the lowest energy $\mathrm{O}-\mathrm{H}$ dissociation transition state does not always coincide with the lowest energy $\mathrm{CH}_{3} \mathrm{OH}$ adsorption. We have identified two unstable 
modes on each surface which we term the "methanol-like" (Figure 7, top) and "methoxylike" (Figure 7, bottom) transition states, due to the similarities of their geometries to the initial and final states, respectively. Similar transition state types have been noted on bimetallic surfaces for $\mathrm{CH}_{3} \mathrm{OH}$ scission by Fajin et al. ${ }^{32}$

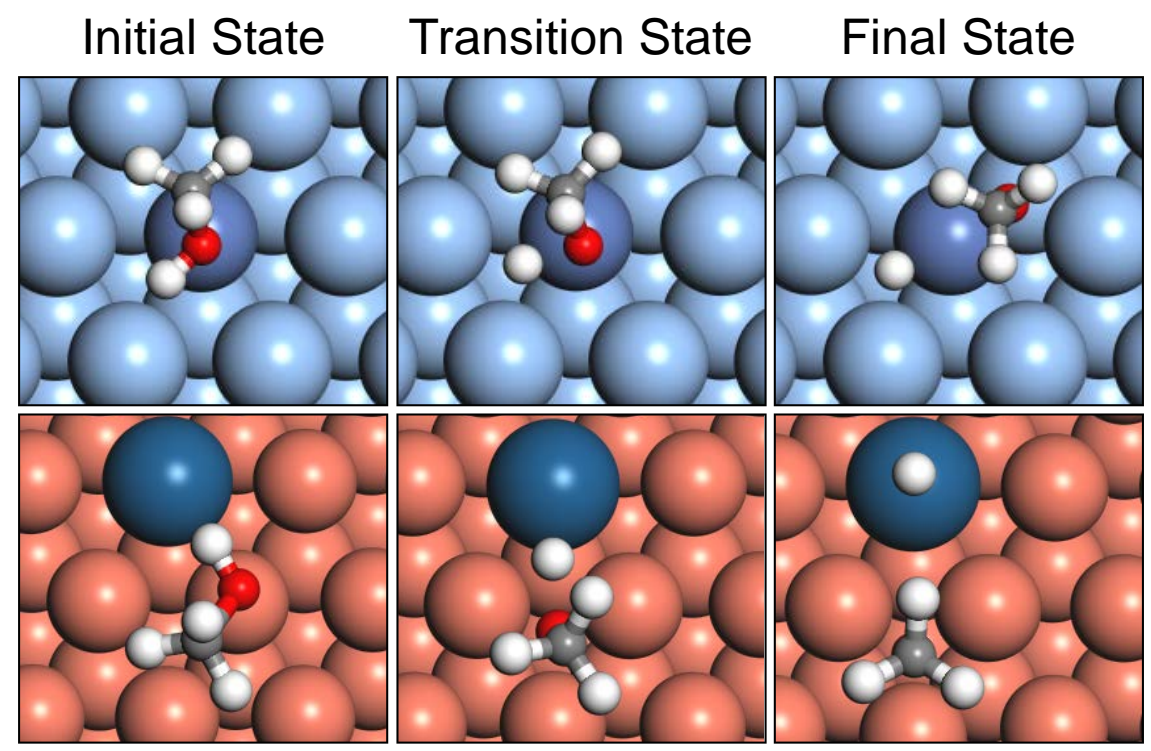

Figure 7: The initial states (left), transition states (middle) and final states (right) for $\mathrm{CH}_{3} \mathrm{OH}$ O-H dissociation on Ni/Ag(111) and Pt/Cu(111) SAAs for the "methanol-like" (top) and "methoxy-like" (bottom) dissociation pathways. A five layer slab was used in these calculations along with a $p(3 \times 3)$ unit cell. Only a portion of the cell is shown for clarity.

The "methanol-like" transition state (Figure 7, top) is located on the dopant atom top site with the dissociating $\mathrm{O}-\mathrm{H}$ bond axis the only major difference in the structure compared to stable $\mathrm{CH}_{3} \mathrm{OH}$ found in the initial state. The $\mathrm{O}-\mathrm{H}$ bond is orientated across shared dopanthost bridge site in the initial state whereas in the transition state the $\mathrm{H}-\mathrm{O}-\mathrm{C}$ angle is reduced, such that the dissociating $\mathrm{O}-\mathrm{H}$ bond is pointed towards the adjacent dopant-host-host hollow site in this case (Figure 7, top). The final state formed from the "methanol-like" transition state has the dissociated $\mathrm{H}$ and $\mathrm{CH}_{3} \mathrm{O}$ fragments separated by the single dopant atom, both adsorbed in shared dopant-host-host hollow sites (Figure 7, top).

On the other hand, the "methoxy-like" transition state (Figure 7, bottom) is positioned on host metal sites that are adjacent to the dopant metal atom. In this case, the single dopant 
atom abstracts the dissociating $\mathrm{H}$ whereas the $\mathrm{CH}_{3} \mathrm{O}$ fragment is stabilised by the host material. The dissociating $\mathrm{O}-\mathrm{H}$ bond axis is near-parallel to the surface and is orientated across the pure metal bridge site formed by two host atoms that are nearest neighbours of the dopant, with the $\mathrm{H}$ closest to the single metal atom (Figure 7, bottom). The $\mathrm{C}-\mathrm{O}$ bond is near-perpendicular to the surface and is close to the final $\mathrm{CH}_{3} \mathrm{O}$ structure (Figure 7, bottom). The dissociated $\mathrm{H}$ and $\mathrm{CH}_{3} \mathrm{O}$ fragments are located on the dopant metal atom and the pure host, respectively (Figure 7, bottom).

The lowest lying transition state varies across the different SAA surfaces, with the majority of SAAs with Au hosts being "methanol-like" and the majority of those with Ag or Cu hosts being "methoxy-like". Dissociation on each of the Ni-doped SAAs proceeds via the "methanol-like" elementary step with activation energies of $0.92 \mathrm{eV}, 1.20 \mathrm{eV}$ and $0.86 \mathrm{eV}$ for $\mathrm{Ni} / \mathrm{Ag}(111), \mathrm{Ni} / \mathrm{Au}(111)$ and Ni/Cu(111), respectively. Similarly, $\mathrm{Pd} / \mathrm{Au}(111), \mathrm{Rh} / \mathrm{Ag}(111)$ and $\mathrm{Rh} / \mathrm{Au}(111)$ also have lowest energy transition states that are "methanol-like", having corresponding kinetic barriers of $1.57 \mathrm{eV}, 0.92 \mathrm{eV}$ and $1.12 \mathrm{eV}$, respectively. The remaining SAA surfaces have more favourable "methoxy-like" transition states. In particular, Pd-, Ptand $\mathrm{Rh}$-doped $\mathrm{Cu}(111)$ have low activation energies for $\mathrm{O}-\mathrm{H}$ scission of $0.87 \mathrm{eV}, 0.74 \mathrm{eV}$ and $0.72 \mathrm{eV}$. We note here that Pt/Cu SAAs can perform highly efficient and selective dry and water co-catalysed dehydrogenation of simple alcohols to aldehydes ${ }^{7,19}$, thereby suggesting this may also be the case for other SAA surfaces with similar energetics. Finally, the remaining SAAs with $\mathrm{Ag}(111)$ hosts offer low-to-intermediate barriers, which are $1.09 \mathrm{eV}$ and $0.80 \mathrm{eV}$ for Pd- and Pt-doped Ag, respectively.

Our calculations show that the activation barriers for $\mathrm{O}-\mathrm{H}$ bond scission are lowered significantly on SAAs compared to their analogous monometallic host materials. In several cases, these barriers are as low as pure Ni, Pd, Pt and Rh. The final dissociated products are bound weakly on most SAA surfaces, with the exception of many of the Pt SAAs due to unusually weak $\mathrm{CH}_{3} \mathrm{O}$ binding compared to $\mathrm{CH}_{3} \mathrm{OH}$ on pure $\mathrm{Pt}(111)$. The weak binding and 
low activation of $\mathrm{CH}_{3} \mathrm{OH}$ on SAAs is suggestive that these surfaces may selectively catalyse $\mathrm{O}-\mathrm{H}$ bond scissions in alcohols without cleaving the $\mathrm{C}-\mathrm{O}$ bond.

\section{Carbon Dioxide Reduction}

The final reaction we have considered in this study is the reduction of $\mathrm{CO}_{2}$ through $\mathrm{C}=\mathrm{O}$ bond scission. We determine that $\mathrm{CO}_{2}$ weakly physisorbs to all SAAs with the $\mathrm{O}=\mathrm{C}=\mathrm{O}$ axis parallel to the surface plane and at a distance of approximately $3 \AA$ to the dopant atom (Figure 8). This configuration is predominantly a van der Waals interaction, thereby giving little variation in the formation energies across the SAAs which are approximately $-0.27 \mathrm{eV}$.

The $\mathrm{C}=\mathrm{O}$ bond activation occurs over shared dopant-host-host hollow sites on all SAAs (Figure 8). The dissociating CO fragment is located at the SAA dopant atom, displaced from the top site, half-way between this site and a shared dopant-host-host hollow site. The dissociating $\mathrm{O}$ fragment is positioned between the shared dopant-host-host hollow site and the adjacent bridge site formed by the same two host atoms. Post-dissociation, the CO fragment relaxes to the dopant top site, whereas the $\mathrm{O}$ adatom relaxes to a pure host hollow site by crossing the host-host bridge site (Figure 8).

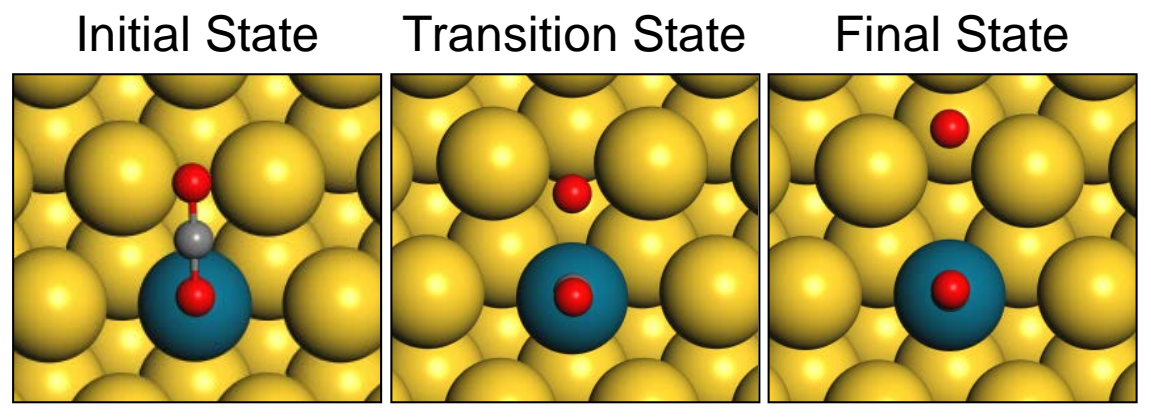

Figure 8: The initial state (left), transition state (middle) and final state (right) for $\mathrm{CO}_{2}$ dissociation on $\mathrm{Pd} / \mathrm{Au}(111) \mathrm{SAA}$. A five layer slab was used in these calculations along with a $\mathrm{p}(3 \times 3)$ unit cell. Only a portion of the cell is shown for clarity.

The dissociation of $\mathrm{C}=\mathrm{O}$ in $\mathrm{CO}_{2}$ is poorly catalysed by pure $\mathrm{Ag}(111)$ and $\mathrm{Au}(111)$ having activation energies of $2.44 \mathrm{eV}$ and $2.95 \mathrm{eV}$, respectively. SAAs of these materials exhibit dramatically lower kinetic barriers, for example Ni-, Pd-, Pt- and Rh-doped Ag(111) have 
activation energies of $0.95 \mathrm{eV}, 1.96 \mathrm{eV}, 1.73 \mathrm{eV}$ and $1.10 \mathrm{eV}$ and those metals doped in $\mathrm{Au}(111)$ have barriers of $1.52 \mathrm{eV}, 2.34 \mathrm{eV}, 2.01 \mathrm{eV}$ and $1.21 \mathrm{eV}$. Ni- and Rh-doped Cu(111) also have significantly reduced activation energies $(0.60 \mathrm{eV}$ and $0.63 \mathrm{eV})$ compared to pure $\mathrm{Cu}(111)$.

A study by Cheng et al. on the competitive pathways for electrochemical $\mathrm{CO}_{2}$ reduction on SAAs indicates that doping $\mathrm{Ag}$ and $\mathrm{Au}$ with transition metal atoms such as $\mathrm{Pd}, \mathrm{Pt}, \mathrm{Co}, \mathrm{Rh}$ and Ir allows for tandem catalysis, where the Au or Ag host material electrochemically reduces $\mathrm{CO}_{2}$ to $\mathrm{CO}^{*}$ which is subsequently reduced by hydrogen at the dopant metal to $\mathrm{C}_{1}$ hydrocarbons. ${ }^{68}$ In that study there is a decoupling of the hydrogen evolution reaction, the $\mathrm{CO}$ oxidation and the CO hydrogen reduction pathways. Our data suggests that the SAAs we have considered, densely sample a wide range of reaction energies and activation energies for $\mathrm{CO}_{2}$ reduction, not all of which are accessible by pure metal surfaces. Thus, SAAs could offer attractive opportunities for tandem catalysis towards the conversion of CO to hydrocarbons.

\section{Brønsted Evans Polanyi Relationships}

Having explored the mechanistic aspects of five simple bond dissociation reactions on SAA surfaces, in this final section we discuss the applicability of the BEP relationship to reactions occurring on SAAs such that it may be employed in the design of these novel materials. The BEP relationship suggests that there is a linear correlation between the reaction energy and activation energy of a chemical reaction. Thus, we use the data reported above to derive BEP relationships for $\mathrm{H}_{2}, \mathrm{CH}_{4}, \mathrm{NH}_{3}, \mathrm{CH}_{3} \mathrm{OH}$ and $\mathrm{CO}_{2}$ bond dissociation reactions and also address the notion of universality in the relations across different surface classes.

Plots of the BEP relationships for each reaction on pure metal and SAA surfaces are given in Figure 9. We model the relationship between the activation energy $\left(\mathrm{E}_{\mathrm{a}}\right)$ and the reaction energy $\left(\Delta \mathrm{E}_{\mathrm{Rxn}}\right)$, plotting the corresponding linear fit for each surface type in Figure $\mathbf{9}$ and reporting the fitted slopes, intercepts, coefficients of determination $\left(R^{2}\right)$ and mean absolute 
errors (MAE) in Table S5. We perform appropriate Student's T-tests (see supporting information for a detailed discussion thereon) to determine whether or not SAAs and pure metals follow the same or unique BEP relationships, giving the full results in Table S5.

In the pure metal case, there are strong linear correlations between $E_{a}$ and $\Delta E_{R \times n}$ for each of these reaction sets with MAEs (and $\mathrm{R}^{2}$ ) in the prediction of $\mathrm{E}_{\mathrm{a}}$ from the linear fits of $0.06 \mathrm{eV}$ (0.98), $0.11 \mathrm{eV}$ (0.95), $0.08 \mathrm{eV}(0.92)$ and $0.11 \mathrm{eV}(0.98)$ for $\mathrm{H}_{2}, \mathrm{CH}_{4}, \mathrm{NH}_{3}$ and $\mathrm{CO}_{2}$ bond scissions, respectively. The correlation in the BEP relation for $\mathrm{CH}_{3} \mathrm{OH}$ on pure metal surfaces is weaker than that for the other reactions $\left(\mathrm{MAE}=0.16 \mathrm{eV}, \mathrm{R}^{2}=0.69\right)$ as a result of $\mathrm{Pt}$, which is an outlier due to exhibiting a low activation barrier though binds $\mathrm{CH}_{3} \mathrm{O}$ weakly which has been previously reported by others. ${ }^{69}$ The slopes of our pure metal BEP linear fits agree well with those of others that include a larger subset of transition metal surfaces than we consider here, though in some cases the intercepts we compute are different as a result of using a non-local functional. ${ }^{30,55}$

Interestingly, across the range of reaction energies considered here, the SAA BEP lines lie below those of the pure metals in all cases. In general, this indicates that for a given reaction energy, the SAAs exhibit lower activation energies than the pure metal surfaces. Thus, a SAA combines both weak binding with low activation energy allowing for optimised catalytic performance.

For the bond dissociation reactions from $\mathrm{H}_{2}, \mathrm{CH}_{4}$, and $\mathrm{NH}_{3}$ (Figure 9), Student's T-test (see supporting information for more detail, Table S5) concludes that the pure metal surfaces and the SAA surfaces follow BEP relationships that are distinct from one another. In the case of $\mathrm{H}_{2}$ activation, the pure metal and SAA BEP relationships have different slopes and intercepts at $95 \%$ confidence level. Similarly, the BEP fits of pure metals and SAAs for $\mathrm{CH}_{4}$ have different intercepts at $95 \%$ confidence level, and those for $\mathrm{NH}_{3}$ dissociation have different intercepts at $90 \%$ confidence, though the slopes of both sets of lines are statistically equal. On the other hand, this is not the case for $\mathrm{CH}_{3} \mathrm{OH}$ and $\mathrm{CO}_{2}$ dissociation (Figure 9), which 
have the same slopes and intercepts at the $90 \%$ confidence interval. Thus, in the cases of $\mathrm{CH}_{3} \mathrm{OH}$ and $\mathrm{CO}_{2}$ bond dissociation reactions, it is appropriate to use a universal scaling relation for both pure metals and SAAs to make predictions about their catalytic performance, though in the cases of $\mathrm{H}_{2}, \mathrm{CH}_{4}$ and $\mathrm{NH}_{3}$ dissociation SAA specific BEP relationships must be used.
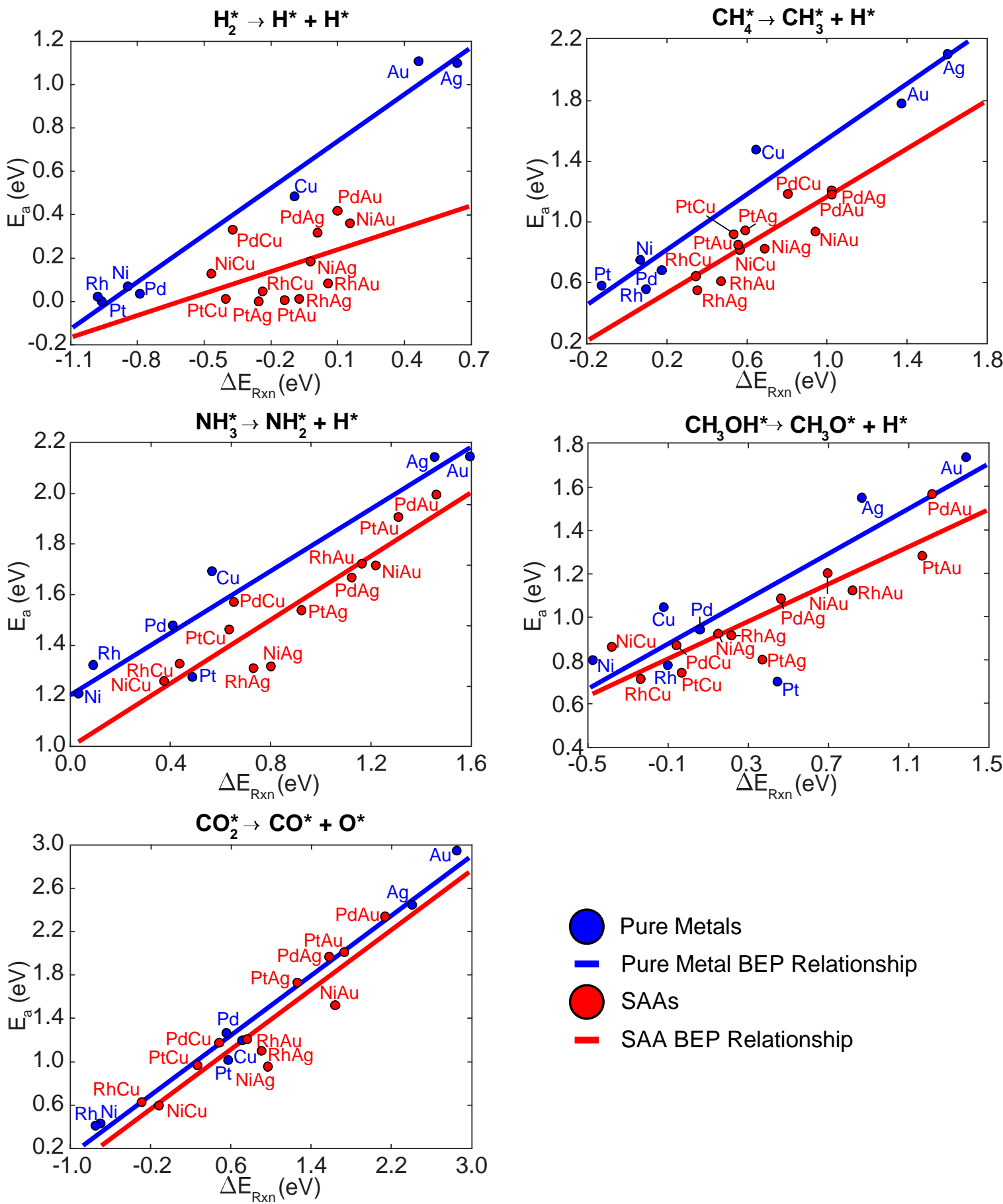

Figure 9: Brønsted-Evans-Polanyi relationships for five simple catalytic bond scissions on pure metal (111) surfaces (blue) and SAA (111) surfaces (red). Plots are of the activation energy (Ea) as a 
function of the reaction energy $\left(\Delta \mathrm{E}_{\mathrm{R} x \mathrm{n}}\right)$. Linear regression fits are drawn for each reaction on each surface type.

Briefly analysing the quality of each BEP linear regression on SAAs (Table S5), we find that for $\mathrm{CH}_{4}, \mathrm{NH}_{3}, \mathrm{CH}_{3} \mathrm{OH}$ and $\mathrm{CO}_{2}$ bond dissociations there are low MAEs (0.08 eV, $0.08 \mathrm{eV}$, $0.09 \mathrm{eV}$ and $0.16 \mathrm{eV}$, respectively) in the prediction of the $\mathrm{E}_{\mathrm{a}}$ from $\Delta \mathrm{E}_{\mathrm{Rxn}}$, in addition to reasonable values for $\mathrm{R}^{2}$ in each case $(0.76,0.83,0.80,0.87$, respectively). On the other hand, for $\mathrm{H}_{2}$ dissociation, the linear fit is poor $\left(\mathrm{R}^{2}=0.20\right)$ and exhibits a MAE of $0.12 \mathrm{eV}$ in the estimation of $E_{a}$, which is significant compared to the average magnitude of $E_{a}$ for this system.

Considering the geometries of the initial, final and transition states during each catalytic bond dissociation, we can provide a qualitative justification to the differences in the pure metal and SAA BEP relationships in a similar way to how we justify formation energy decoupling in the context of TCS. In the case of those reactions that form distinct BEP relationships, we note that the initial and transition states are stabilised primarily by the dopant metal atom whereas the final dissociated states (due to a reduction in the fragment valency) are bound to a combination of shared dopant-host sites. Thus, the poor charge mixing between the dopant and host metals as described by Thirumalai and Kitchin ${ }^{57}$, results in the transition states being additionally stabilised compared to the final states for these reactions on SAAs. However with $\mathrm{CO}_{2}$ dissociation for example, this is not the case; the dissociating $\mathrm{O}$ adatom is located on a pure host bridge site and the dissociating $\mathrm{CO}$ fragment is on the dopant top site in both the transition and the final state; thus, both states are stabilised to the same degree.

\section{Conclusions}

We have presented a comprehensive study of the reactivity of SAAs in which platinum group metals are doped at the single atom limit into noble metal hosts. We have investigated the adsorption behaviour of a variety of catalytically relevant species as well as the kinetics of 
several simple, yet highly relevant bond dissociation reactions on these materials through the use of DFT.

Our calculations show that SAAs typically offer intermediate binding strength compared to the corresponding monometallic dopant and host surfaces, though in some cases SAAs including Rh- and Ni-doped Ag and Au, actually exhibit enhanced reactivity towards adsorbates. We determine that SAAs are subject to the simple adsorption valency rules that are generally followed by pure metal surfaces ${ }^{53}$, whereby the binding site preference (e.g. on top, bridge or hollow sites) is given by the number of dangling bonds in the adsorbate. An interesting consequence of this, is that SAAs strongly adhere to pure metal TCS when the most stable adsorption site of each fragment is the same, though deviate when this is not the case.

Our investigation into the kinetics of simple, catalytically relevant bond dissociation reactions showed that SAAs combine weak binding and low activation energies for bond dissociations in $\mathrm{H}_{2}, \mathrm{CH}_{4}$ and $\mathrm{NH}_{3}$, as well as very low activation energies for the $\mathrm{CO}$ oxidation reaction and $\mathrm{CH}_{3} \mathrm{OH}$ dissociation in several cases. Finally, we determined BEP relationships for these bond dissociations on SAAs noting that they may deviate from those on pure metal surfaces as a result of relative changes in the dopant/host bonding contributions to the transition state and to the final state. The large amount of data presented in this article, along with our interpretations, will aid in the discovery and development of SAA materials that exhibit unique and exciting catalytic behaviour.

\section{Acknowledgements}

M.T.D. is funded by the Engineering and Physical Sciences Research Council (EPSRC) UK as part of a Doctoral Training Grant. R. R. was supported as part of the Integrated Mesoscale Architectures for Sustainable Catalysis (IMASC), an Energy Frontier Research Center funded by the U.S. Department of Energy, Office of Science, Office of Basic Energy Sciences under Award Number DE-SC0012573. The authors acknowledge the use of the 
UCL High Performance Computing Facilities (Legion@UCL and Grace@UCL), and associated support services, in the completion of the computational part of this work. This research used resources of the Oak Ridge Leadership Computing Facility, which is a DOE Office of Science User Facility supported under Contract DE-AC05-000R22725. A.M.'s work was supported by the European Research Council under the European Union's Seventh Framework Programme (FP/2007-2013)/ERC Grant Agreement No. 616121 (Heterolce project) and the Royal Society through a Wolfson Research Merit Award. E.C.H.S. thanks the Division of Chemical Sciences, Office of Basic Energy Sciences, CPIMS Program, U.S. Department of Energy, under Grant No. FG02-10ER16170 for the financial support of this work.

Supporting Information. Additional data, including lattice constants, formation energies of fragments, activation and reaction energies of dissociation reactions, parameters of thermochemical scaling and BEP relations. Equilibrium surface coverages from Fermi-Dirac statistics. Details of Student's T-tests. This material is available free of charge via the Internet at http://pubs.acs.org.

\section{References}

(1) Greeley, J.; Mavrikakis, M. Alloy Catalysts Designed from First Principles. Nat. Mater. 2004, 3 , 810-815.

(2) Besenbacher, F.; Chorkendorff, I.; Clausen, B. S.; Hammer, B.; Molenbroek, A. M.; Nørskov, J. K.; Stensgaard, I. Design of a Surface Alloy Catalyst for Steam Reforming. Science 1998, 279, 1913-1915.

(3) Kyriakou, G.; Boucher, M. B.; Jewell, A. D.; Lewis, E. A.; Lawton, T. J.; Baber, A. E.; Tierney, H. L.; Flytzani-Stephanopoulos, M.; Sykes, E. C. H. Isolated Metal Atom Geometries as a Strategy for Selective Heterogeneous Hydrogenations. Science 2012, 335, 1209-1212.

(4) Marcinkowski, M. D.; Jewell, A. D.; Stamatakis, M.; Boucher, M. B.; Lewis, E. A.; Murphy, C. J.; Kyriakou, G.; Sykes, E. C. H. Controlling a Spillover Pathway with the Molecular Cork Effect. Nat. Mater. 2013, 12, 523-528.

(5) Marcinkowski, M. D.; Darby, M. T.; Liu, J.; Wimble, J. M.; Lucci, F. R.; Lee, S.; Michaelides, A.; Flytzani-Stephanopoulos, M.; Stamatakis, M.;Sykes, E. C. H. Pt/Cu Single-Atom Alloys as CokeResistant Catalysts for Efficient C-H Activation. Nat. Chem. 2018.

(6) Liu, J.; Shan, J.; Lucci, F. R.; Cao, S.; Sykes, E. C. H.; Flytzani-Stephanopoulos, M. Palladium-Gold Single Atom Alloy Catalysts for Liquid Phase Selective Hydrogenation of 1-Hexyne. Catal. Sci. Technol. 2017, 7, 4276-4284.

(7) Shan, J.; Lucci, F. R.; Liu, J.; El-Soda, M.; Marcinkowski, M. D.; Allard, L. F.; Sykes, E. C. H.; Flytzani-Stephanopoulos, M. Water Co-Catalyzed Selective Dehydrogenation of Methanol to Formaldehyde and Hydrogen. Surf. Sci. 2016, 650, 121-129. 
(8) Lucci, F. R.; Liu, J.; Marcinkowski, M. D.; Yang, M.; Allard, L. F.; Flytzani-Stephanopoulos, M.; Sykes, E. C. H. Selective Hydrogenation of 1,3-Butadiene on Platinum-Copper Alloys at the SingleAtom Limit. Nat. Comm. 2015, 6, 8550.

(9) Shan, J.; Liu, J.; Li, M.; Lustig, S.; Lee, S.; Flytzani-Stephanopoulos, M. Nicu Single Atom Alloys Catalyze the Ch Bond Activation in the Selective Non- Oxidative Ethanol Dehydrogenation Reaction. Appl. Catal. B-Environ. 2018, 226, 534-543.

(10) Shan, J.; Janvelyan, N.; Li, H.; Liu, J.; Egle, T. M.; Ye, J.; Biener, M. M.; Biener, J.; Friend, C. M.; Flytzani-Stephanopoulos, M. Selective Non-Oxidative Dehydrogenation of Ethanol to Acetaldehyde and Hydrogen on Highly Dilute Nicu Alloys. Appl. Catal. B-Environ. 2017, 205, 541-550.

(11) Wang, Z.-T.; Darby, M. T.; Therrien, A. J.; El-Soda, M.; Michaelides, A.; Stamatakis, M.; Sykes, E. C. H. Preparation, Structure, and Surface Chemistry of Ni-Au Single Atom Alloys. J. Phys. Chem. C 2016, 120, 13574-13580.

(12) Lucci, F. R.; Lawton, T. J.; Pronschinske, A.; Sykes, E. C. H. Atomic Scale Surface Structure of $\mathrm{Pt} / \mathrm{Cu}(111)$ Surface Alloys.J. Phys. Chem. C 2014, 118, 3015-3022.

(13) Baber, A. E.; Tierney, H. L.; Lawton, T. J.; Sykes, E. C. H. An Atomic-Scale View of Palladium Alloys and Their Ability to Dissociate Molecular Hydrogen. ChemCatChem 2011, 3, 607-614.

(14) Tierney, H. L.; Baber, A. E.; Sykes, E. C. H. Atomic-Scale Imaging and Electronic Structure Determination of Catalytic Sites on Pd/Cu near Surface Alloys. J. Phys. Chem. C 2009, 113, 72467250.

(15) Tierney, H. L.; Baber, A. E.; Kitchin, J. R.; Sykes, E. C. H. Hydrogen Dissociation and Spillover on Individual Isolated Palladium Atoms. Phys. Rev. Lett. 2009, 103, 246102.

(16) Lucci, F. R.; Darby, M. T.; Mattera, M. F. G.; Ivimey, C. J.; Therrien, A. J.; Michaelides, A.; Stamatakis, M.; Sykes, E. C. H. Controlling Hydrogen Activation, Spillover, and Desorption with Pd-Au Single-Atom Alloys. The Journal of Physical Chemistry Letters 2016, 7, 480-485.

(17) Lucci, F. R.; Marcinkowski, M. D.; Lawton, T. J.; Sykes, E. C. H. H2 Activation and Spillover on Catalytically Relevant Pt-Cu Single Atom Alloys. J. Phys. Chem. C 2015, 119, 24351-24357.

(18) Boucher, M. B.; Zugic, B.; Cladaras, G.; Kammert, J.; Marcinkowski, M. D.; Lawton, T. J.; Sykes, E. C. H.; Flytzani-Stephanopoulos, M. Single Atom Alloy Surface Analogs in Pd0.18cu15 Nanoparticles for Selective Hydrogenation Reactions. Phys. Chem. Chem. Phys. 2013, 15, 12187-12196.

(19) Wang, Z.-T.; Hoyt, R. A.; El-Soda, M.; Madix, R. J.; Kaxiras, E.; Sykes, E. C. H. Dry Dehydrogenation of Ethanol on Pt-Cu Single Atom Alloys. Top. Catal. 2017.

(20) Marcinkowski, M. D.; Liu, J.; Murphy, C. J.; Liriano, M. L.; Wasio, N. A.; Lucci, F. R.; FlytzaniStephanopoulos, M.; Sykes, E. C. H. Selective Formic Acid Dehydrogenation on Pt-Cu Single-Atom Alloys. ACS Catal. 2017, 7, 413-420.

(21) Darby, M. T.; Sykes, E. C. H.; Michaelides, A.; Stamatakis, M. Carbon Monoxide Poisoning Resistance and Structural Stability of Single Atom Alloys. Top. Catal. 2018, DOI: 10.1007/s11244-0170882-1.

(22) Liu, J.; Lucci, F. R.; Yang, M.; Lee, S.; Marcinkowski, M. D.; Therrien, A. J.; Williams, C. T.; Sykes, E. C. H.; Flytzani-Stephanopoulos, M. Tackling Co Poisoning with Single-Atom Alloy Catalysts. J. Am. Chem. Soc. 2016, 138, 6396-6399.

(23) Neurock, M. Perspectives on the First Principles Elucidation and the Design of Active Sites. J. Catal. 2003, 216, 73-88.

(24) Montemore, M. M.; Medlin, J. W. Scaling Relations between Adsorption Energies for Computational Screening and Design of Catalysts. Catal. Sci. Technol. 2014, 4, 3748-3761.

(25) Greeley, J. Theoretical Heterogeneous Catalysis: Scaling Relationships and Computational Catalyst Design. Annual Review of Chemical and Biomolecular Engineering 2016, 7, 605-635.

(26) Norskov, J. K.; Bligaard, T.; Rossmeisl, J.; Christensen, C. H. Towards the Computational Design of Solid Catalysts. Nat Chem 2009, 1, 37-46.

(27) Abild-Pedersen, F.; Greeley, J.; Studt, F.; Rossmeisl, J.; Munter, T. R.; Moses, P. G.; Skúlason, E.; Bligaard, T.; Nørskov, J. K. Scaling Properties of Adsorption Energies for Hydrogen-Containing Molecules on Transition-Metal Surfaces. Phys. Rev. Lett. 2007, 99, 016105. 
(28) Pallassana, V.; Neurock, M. Electronic Factors Governing Ethylene Hydrogenation and Dehydrogenation Activity of Pseudomorphic Pdml/Re(0001), Pdml/Ru(0001), $\mathrm{Pd}(111)$, and Pdml/Au(111) Surfaces. J. Catal. 2000, 191, 301-317.

(29) Liu, Z.-P.; Hu, P. General Trends in Co Dissociation on Transition Metal Surfaces. J. Chem. Phys. 2001, 114, 8244-8247.

(30) Michaelides, A.; Liu, Z. P.; Zhang, C. J.; Alavi, A.; King, D. A.; Hu, P. Identification of General Linear Relationships between Activation Energies and Enthal py Changes for Dissociation Reactions at Surfaces. J. Am. Chem. Soc. 2003, 125, 3704-3705.

(31) Santen, R. A. v.; Neurock, M.; Shetty, S. G. Reactivity Theory of Transition-Metal Surfaces: A Brønsted-Evans-Polanyi Linear Activation Energy-Free-Energy Analysis. Chem. Rev. 2010, 110, 20052048.

(32) Fajin, J. L. C.; Cordeiro, M. N. D. S.; Gomes, J. R. B. Methanol Dissociation on Bimetallic Surfaces: Validity of the General Bronsted-Evans-Polanyi Relationship for O-H Bond Cleavage. RSC Adv. 2016, 6, 18695-18702.

(33) Fajín, J. L. C.; Cordeiro, M. N. D. S.; Illas, F.; Gomes, J. R. B. Generalized Brønsted-Evans-Polanyi Relationships and Descriptors for O-HBond Cleavage of Organic Molecules on Transition Metal Surfaces. J. Catal. 2014, 313, 24-33.

(34) Viñes, F.; Vojvodic, A.; Abild-Pedersen, F.; Illas, F. Brønsted-Evans-Polanyi Relationship for Transition Metal Carbide and Transition Metal Oxide Surfaces. J. Phys. Chem. C 2013, 117, 41684171.

(35) Mehmood, F.; Rankin, R. B.; Greeley, J.; Curtiss, L. A. Trends in Methanol Decomposition on Transition Metal Alloy Clusters from Scaling and Bronsted-Evans-Polanyi Relationships. Phys. Chem. Chem. Phys. 2012, 14, 8644-8652.

(36) Vojvodic, A.; Calle-Vallejo, F.; Guo, W.; Wang, S.; Toftelund, A.; Studt, F.; Martínez, J. I.; Shen, J.; Man, I. C.; Rossmeisl, J.; Bligaard, T.; Nørskov, J. K.; Abild-Pedersen, F. On the Behavior of Brønsted-Evans-Polanyi Relations for Transition Metal Oxides.J. Chem. Phys. 2011, 134, 244509.

(37) Bligaard, T.; Nørskov, J. K.; Dahl, S.; Matthiesen, J.; Christensen, C. H.; Sehested, J. The Brønsted-Evans-Polanyi Relation and the Volcano Curve in Heterogeneous Catalysis. J. Catal. 2004, 224, 206-217.

(38) Logadottir, A.; Rod, T. H.; Nørskov, J. K.; Hammer, B.; Dahl, S.; Jacobsen, C. J. H. The BrønstedEvans-Polanyi Relation and the Volcano Plot for Ammonia Synthesis over Transition Metal Catalysts. J. Catal. 2001, 197, 229-231.

(39) Ferrin, P.; Nilekar, A. U.; Greeley, J.; Mavrikakis, M.; Rossmeisl, J. Reactivity Descriptors for Direct Methanol Fuel Cell Anode Catalysts. Surf. Sci. 2008, 602, 3424-3431.

(40) Liu, B.; Greeley, J. Decomposition Pathways of Glycerol Via C-H, O-H, and C-C Bond Scission on Pt(111): A Density Functional Theory Study. J. Phys. Chem. C 2011, 115, 19702-19709.

(41) Yoo, J. S.; Abild-Pedersen, F.; Nørskov, J. K.; Studt, F. Theoretical Analysis of Transition-Metal Catalysts for Formic Acid Decomposition. ACS Catal. 2014, 4, 1226-1233.

(42) Kresse, G.; Hafner, J. \Textit\{Ab Initio\} Molecular Dynamics for Liquid Metals. Physical Review $B$ 1993, 47, 558-561.

(43) Dong, W.; Kresse, G.; Furthmüller, J.; Hafner, J. Chemisorption of H on $\mathrm{Pd}(111)$ : An $<1>A b</ I>$ $<$ I>Initio</I>Approach with Ultrasoft Pseudopotentials. Phys. Rev. B 1996, 54, 2157-2166.

(44) Kresse, G.; Furthmüller, J. Efficiency of Ab-Initio Total Energy Calculations for Metals and Semiconductors Using a Plane-Wave Basis Set. Comp Mater Sci 1996, 6, 15-50.

(45) Blöchl, P. E. Projector Augmented-Wave Method. Phys. Rev. B 1994, 50, 17953-17979.

(46) Kresse, G.; Joubert, D. From Ultrasoft Pseudopotentials to the Projector Augmented-Wave Method. Phys. Rev. B 1999, 59, 1758-1775.

(47) Klimeš, J.; Bowler, D. R.; Michaelides, A. Chemical Accuracy for the Van Der Waals Density Functional. J. Phys. Condens. Matter. 2010, 22, 022201.

(48) Klimeš, J.; Bowler, D. R.; Michaelides, A. Van Der Waals Density Functionals Applied to Solids. Phys. Rev. B 2011, 83, 195131. 
(49) Klimeš, J.; Michaelides, A. Perspective: Advances and Challenges in Treating Van Der Waals Dispersion Forces in Density Functional Theory. J. Chem. Phys. 2012, 137, 120901.

(50) Dion, M.; Rydberg, H.; Schröder, E.; Langreth, D. C.; Lundqvist, B. I. Van Der Waals Density Functional for General Geometries. Phys. Rev. Lett. 2004, 92, 246401.

(51) Henkelman, G.; Uberuaga, B. P.; Jónsson, H. A Climbing Image Nudged Elastic Band Method for Finding Saddle Points and Minimum Energy Paths. J. Chem. Phys. 2000, 113, 9901-9904.

(52) Henkelman, G.; Jónsson, H. A Dimer Method for Finding Saddle Points on High Dimensional Potential Surfaces Using Only First Derivatives. J. Chem. Phys. 1999, 111, 7010-7022.

(53) Michaelides, A.; Hu, P. Insight into Microscopic Reaction Pathways in Heterogeneous Catalysis. J. Am. Chem. Soc. 2000, 122, 9866-9867.

(54) Fernández, E. M.; Moses, P. G.; Toftelund, A.; Hansen, H. A.; Martínez, J. I.; Abild-Pedersen, F.; Kleis, J.; Hinnemann, B.; Rossmeisl, J.; Bligaard, T.; Nørskov, J. K. Scaling Relationships for Adsorption Energies on Transition Metal Oxide, Sulfide, and Nitride Surfaces. Angew. Chem. Int. Edit. 2008, 47, 4683-4686.

(55) Wang, S.; Petzold, V.; Tripkovic, V.; Kleis, J.; Howalt, J. G.; Skulason, E.; Fernandez, E. M.; Hvolbaek, B.; Jones, G.; Toftelund, A.; Falsig, H.; Bjorketun, M.; Studt, F.; Abild-Pedersen, F.; Rossmeisl, J.; Norskov, J. K.; Bligaard, T. Universal Transition State Scaling Relations for (De)Hydrogenation over Transition Metals. Phys. Chem. Chem. Phys. 2011, 13, 20760-20765.

(56) Montemore, M. M.; Medlin, J. W. Site-Specific Scaling Relations for Hydrocarbon Adsorption on Hexagonal Transition Metal Surfaces. J. Phys. Chem. C 2013, 117, 20078-20088.

(57) Thirumalai, H.; Kitchin, J. R. Investigating the Reactivity of Single Atom Alloys Using Density Functional Theory. Top. Catal. 2018.

(58) Inderwildi, O. R.; Jenkins, S. J.; King, D. A. When Adding an Unreactive Metal Enhances Catalytic Activity: Nox Decomposition over Silver-Rhodium Bimetallic Surfaces. Surf. Sci. 2007, 601, L103L108.

(59) Michaelides, A. The Unhappy Marriage of Transition and Noble Metal Atoms: A New Way to Enhance Catalytic Activity? (a Perspective On: "When Adding an Unreactive Metal Enhances Catalytic Activity: Nox Decomposition over Silver-Rhodium Bimetallic Surfaces" by O.R. Inderwildi, S.J. Jenkins, D.A. King). Surf. Sci. 2007, 601, 3529-3531.

(60) Hensley, A. J. R.; Ghale, K.; Rieg, C.; Dang, T.; Anderst, E. S.; Studt, F.; Campbell, C. T.; McEwen, J.-S.; Xu, Y. A Dft-Based Method for More Accurate Adsorption Energies: An Adaptive Sum of Energies from Rpbe and Vdw Density Functionals. J. Phys. Chem. C 2017.

(61) Gautier, S.; Steinmann, S. N.; Michel, C.; Fleurat-Lessard, P.; Sautet, P. Molecular Adsorption at Pt(111). How Accurate Are Dft Functionals? Phys. Chem. Chem. Phys. 2015, 17, 28921-28930.

(62) Zeigarnik, A. V.; Valdés-Pérez, R. E.; Myatkovskaya, O. N. C-C Bond Scission in Ethane Hydrogenolysis. J. Phys. Chem. B 2000, 104, 10578-10587.

(63) Lin, J. L.; Bent, B. E. lodomethane Dissociation on Cu(111): Bonding and Chemistry of Adsorbed Methyl Groups. Journal of Vacuum Science \& Technology A: Vacuum, Surfaces, and Films 1992, 10, 2202-2209.

(64) Canning, N. D. S.; Baker, M. D.; Chesters, M. A. Ethylene and Acetylene Adsorption on Cu(111) and Pt(111) Studied by Auger Spectroscopy. Surf. Sci. 1981, 111, 441-451.

(65) Paul, A.; Yang, M. X.; Bent, B. E. Disproportionation and Coupling Reactions of Alkyl lodides on a Au(111) Surface. Surf. Sci. 1993, 297, 327-344.

(66) Calle-Vallejo, F.; Loffreda, D.; Koper, M. T. M.; Sautet, P. Introducing Structural Sensitivity into Adsorption-Energy Scal ing Relations by Means of Coordination Numbers. Nat. Chem. 2015, 7, 403410.

(67) Lawton, T. J.; Carrasco, J.; Baber, A. E.; Michaelides, A.; Sykes, E. C. H. Visualization of Hydrogen Bonding and Associated Chirality in Methanol Hexamers. Phys. Rev. Lett. 2011, 107, 256101.

(68) Cheng, M.-J.; Clark, E. L.; Pham, H. H.; Bell, A. T.; Head-Gordon, M. Quantum Mechanical Screening of Single-Atom Bimetallic Alloys for the Selective Reduction of Co2 to C1 Hydrocarbons. ACS Catal. 2016, 6, 7769-7777. 
(69) Greeley, J.; Mavrikakis, M. A First-Principles Study of Methanol Decomposition on Pt(111). J. Am. Chem. Soc. 2002, 124, 7193-7201. 


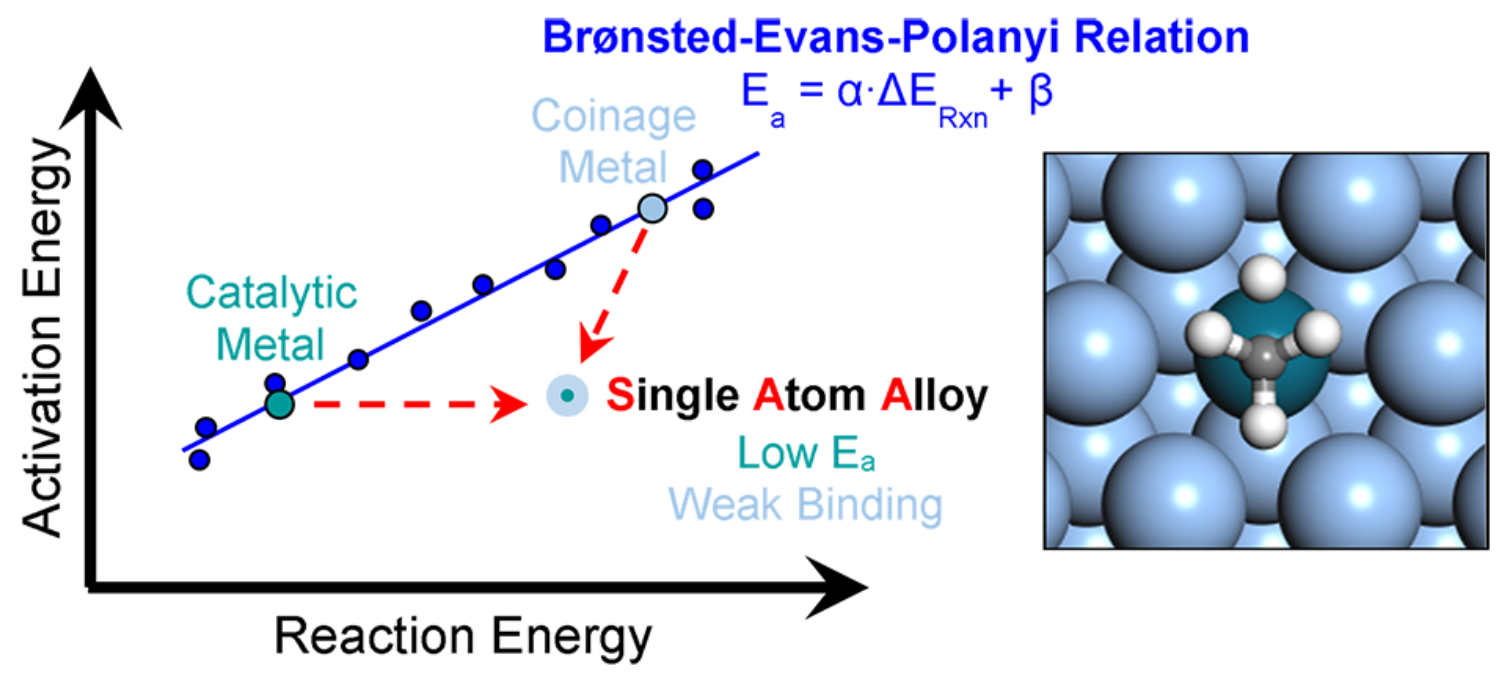

